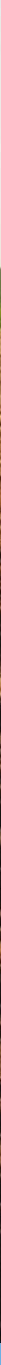

\title{
Gebruik van ijzerwater en fulvozuur als ijzermeststof - laboratoriumtesten
}

Inge Regelink, René Rietra, Rob Comans 



\section{Gebruik van ijzerwater en fulvozuur als ijzermeststof - laboratoriumtesten}

Inge Regelink ${ }^{1}$, René Rietra ${ }^{1}$, Rob Comans ${ }^{2}$

1 Wageningen Environmental Research

2 Department of Soil Quality, Wageningen University

Dit onderzoek is uitgevoerd door Wageningen University (Sectie Bodemkwaliteit) en Wageningen Environmental Research in opdracht van Vitens B.V. en met een financiële bijdrage vanuit TKI Deltatechnologie.

Wageningen Environmental Research

Wageningen, maart 2018

Rapport 2875

ISSN 1566-7197 
Regelink, I.C., Rietra, R.P.J.J., Comans, R.N.J., 2018. Gebruik van ijzerwater en fulvozuur als ijzermeststof - laboratoriumtesten. Wageningen, Wageningen Environmental Research, Rapport 2875. 34 blz.; 16 fig.; 16 tab.; 11 ref.

Bij de productie van drinkwater uit grondwater worden grote hoeveelheden ijzerslib geproduceerd. Dit rapport bevat resultaten van lab-experimenten die een eerste verkenning vormen naar de mogelijkheden om ijzerslib, al dan niet in combinatie met fulvozuur, te gebruiken als ijzermeststof in de land- en tuinbouw.

Iron sludge is a waste stream that is produced during production of drinking water from ground water. This report describes results from laboratory experiments which are meant to explore the perspectives of the use of iron sludge as an iron nutrient to be used in horticulture and agriculture.

Trefwoorden: ijzerchelaat, chlorose, ijzerslib, fulvozuur, iron chelate, iron sludge, fulvic acid, iron chlorisis

Dit rapport is gratis te downloaden van https://doi.org/10.18174/444515 of op www.wur.nl/environmental-research (ga naar 'Wageningen Environmental Research' in de grijze balk onderaan). Wageningen Environmental Research verstrekt geen gedrukte exemplaren van rapporten.

() 2018 Wageningen Environmental Research (instituut binnen de rechtspersoon Stichting Wageningen Research), Postbus 47, 6700 AA Wageningen, T 03174807 00, www.wur.nl/environmental-research. Wageningen Environmental Research is onderdeel van Wageningen University \& Research.

- Overname, verveelvoudiging of openbaarmaking van deze uitgave is toegestaan mits met duidelijke bronvermelding.

- Overname, verveelvoudiging of openbaarmaking is niet toegestaan voor commerciële doeleinden en/of geldelijk gewin.

- Overname, verveelvoudiging of openbaarmaking is niet toegestaan voor die gedeelten van deze uitgave waarvan duidelijk is dat de auteursrechten liggen bij derden en/of zijn voorbehouden.

Wageningen Environmental Research aanvaardt geen aansprakelijkheid voor eventuele schade voortvloeiend uit het gebruik van de resultaten van dit onderzoek of de toepassing van de adviezen. 


\section{Inhoud}

Samenvatting $\quad \mathbf{5}$

$\begin{array}{llr}1 & \text { Inleiding } & 7\end{array}$

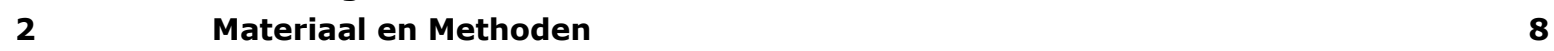

2.1 Materialen $\quad 8$

2.2 Methoden 9

2.2.1 Karakterisatie ijzerslib en HumVi (2015) 9

2.2.2 Laboratoriumtesten (2016) 10

2.2.3 Testen stabiliteit Fe-HumVi in bodem 10

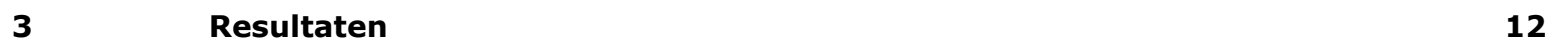

3.1 Karakterisatie ijzerspoelwater en ijzerslib 12

3.1.1 Samenstelling $\quad 12$

3.1.2 Deeltjesgrootte en oppervlaktespanning 14

3.1.3 Samenstelling HumVi 15

3.1.4 Samenstelling van de waterfase van ijzerslib met en zonder HumVi 16

3.2 Laboratoriumproeven ijzerslib en HumVi 18

3.2.1 Samenstelling ijzerwater en ijzerslib 18

3.2.2 Effect van HumVi dosering op de ijzerconcentraties in het supernatant 18

$\begin{array}{ll}3.2 .3 \text { IJzerspeciatie in het supernatant } & 20\end{array}$

$\begin{array}{lll}3.3 & \text { Stabiliteit van Fe-HumVi in de bodem } & 23\end{array}$

3.3.1 Test $1 \quad 23$

$\begin{array}{ll}3.3 .2 \text { Test } 2 & 26\end{array}$

$4 \quad$ Synthese en conclusie $\quad 31$

$\begin{array}{ll}\text { Literatuur } & 33\end{array}$ 



\section{Samenvatting}

Bij de productie van drinkwater uit grondwater worden grote hoeveelheden ijzerslib gevormd. Daarnaast wordt bij de ontkleuring van drinkwater uit bronnen gelegen onder veenpakketten een fulvozuur-rijke reststroom (HumVi) geproduceerd. Vitens wil de mogelijkheden onderzoeken om deze twee reststromen, na een eventuele opwerkingsstap, af te zetten als ijzermeststoffen voor toepassing in de land- en tuinbouw. Als eerste verkenning is een serie laboratoriumexperimenten met ijzerslib, HumVi en synthetische ijzerchelaten uitgevoerd waarvan de resultaten zijn opgenomen in dit rapport.

Allereerst is een uitvoerige karakterisatie van ijzerspoelwater (niet ingedikt) en ijzerslib (ingedikt door middel van een poly-electroliet) uitgevoerd, waarbij zowel de samenstelling als de fysische eigenschappen zijn bepaald. De analyses zijn uitgevoerd op monsters van zes drinkwaterproductielocaties om de variatie hiertussen in beeld te kunnen brengen. Hieruit blijkt dat ijzerslib op drogestofbasis voor 30-40\% bestaat uit het element ijzer, wat overeenkomt met een ijzerhydroxide $(\mathrm{FeOOH})$-gehalte van $50-75 \%$. Het kalkgehalte is sterk afhankelijk van de locatie en varieert van 1 tot $30 \%$. Daarnaast bevat ijzerslib circa 8 tot $14 \%$ organische stof dat voor meer dan $95 \%$ gebonden is aan de vaste fase (i.e. de ijzerhydroxiden). Om een dergelijk hoge bindingscapaciteit van de ijzerhydroxiden te verklaren, moeten de ijzerhydroxiden zeer kleine deeltjes vormen van circa $10 \mathrm{~nm}$. Deze nanodeeltjes klonteren samen tot collö̈den van enkele tientallen micrometers groot zoals is vastgesteld door middel van een Coulter-teller. In ijzerslib (met polyelectroliet) zijn de gevormde colloïden groter dan in ijzerspoelwater. Er trad geen verandering op in de grootte gedurende een periode van twee maanden.

Het aandeel plantbeschikbaar ijzer in ijzerslib wordt als zeer laag beoordeeld wanneer deze wordt gebaseerd op het wateroplosbare ijzer $(<1 \%)$ of het DTPA-extraheerbare ijzer $(<5 \%)$. Na toevoeging van HumVi dispergeren de ijzerhydroxide deeltjes tot zeer kleine nanodeeltjes welke goed in oplossing blijven. Bij de Fe-HumVi mengsels bevindt 10-40\% van het ijzer zich in het supernatant tegen $<1 \%$ voor ijzerslib monster zónder HumVi. Met het supernatant wordt hier de waterfase bedoeld welke resteert na centrifugeren van ijzerslib of Fe-HumVi. Circa de helft van de ijzerdeeltjes in Fe-HumVi is dusdanig klein dat deze geclassificeerd kunnen worden als nanodeeltjes. De geteste Fe-HumVi mengsels bevatten $5-25 \%$ (v/v) HumVi.

Uit testen met Fe-HumVi en grondmonsters blijkt dat Fe-HumVi, net als ijzerchelaten, in staat is om de ijzerconcentratie in het bodemvocht gedurende een aantal weken te verhogen. De stabiliteit van Fe-HumVi verschilt echter sterk tussen verschillende grondsoorten, wat niet verklaard kan worden op basis van bodemeigenschappen. In een aantal gronden wordt na 14 dagen nog 50 tot $80 \%$ van het gedoseerde ijzer in de waterfase teruggevonden. In andere gronden is dit minder dan $5 \%$. Onder dezelfde condities blijft het ijzerchelaat Fe-DPTA voor 50-100\% stabiel (minder stabiel bij hogere $\mathrm{pH}$ ) en Fe-HBED voor 90-100\%. Voor deze testen is Fe-HumVi toegevoegd aan grond-watersuspensies, zodat analyse van de waterfractie mogelijk wordt. Hierdoor zijn de resultaten echter niet een-op-een te vertalen naar veldvochtige gronden vanwege het hogere vochtgehalte in de test in vergelijking met veldvochtige gronden.

In labtesten is aangetoond dat Fe-HumVi de ijzerconcentratie van bodemvocht kan verhogen, maar dat dit effect niet in alle grondsoorten optreedt. De werkzaamheid van ijzerslib en Fe-HumVi als ijzermeststof moet onderzocht worden in potproeven met ijzer-deficiënte grond en ijzerbehoeftige gewassen. 


\section{$1 \quad$ Inleiding}

Bij het produceren van drinkwater uit diep grondwater wordt, afhankelijk van de locatie, in meerdere of mindere mate ijzerwater geproduceerd. Dit ijzerwater ontstaat door oxidatie van opgelost ijzer en is oranjebruin van kleur. IJzerwater wordt vervolgens ingedikt tot ijzerslib, waarbij indien nodig een polymeer (PE) wordt toegevoegd. Het gevormde restproduct wordt o.a. gebruikt voor het binden van zwavel in vergistingsinstallaties en het binden van fosfaat in afvalwaterzuiveringen of in natuurgebieden. Daarnaast wordt bij de ontkleuring van drinkwater d.m.v. anionenwisselaars een fulvozuurrijke reststroom genaamd HumVi geproduceerd. Dit product wordt als biostimulant/groeiverbeterend middel afgezet naar de landbouw. Om ijzerslib in de toekomst verder te valoriseren, is Vitens op zoek naar alternatieve afzetmogelijkheden voor ijzerslib. In dat kader heeft Vitens ingezet op onderzoek naar de perspectieven van het gebruik van ijzerslib, al dan niet in combinatie met HumVi, als ijzermeststof in de land- en tuinbouw.

IJzermeststoffen worden in Nederland gebruikt in de glastuinbouw. In de rest van de landbouw is het gebruik beperkt tot de teelt van gewassen die gevoelig zijn voor ijzertekort (o.a. perenteelt, druiventeelt). IJzer-deficiënte gronden komen, bij het hanteren van internationale criteria, in Nederland eigenlijk niet voor. De oplosbaarheid van ijzerhydroxide mineralen neemt sterk af met een toenemende $\mathrm{pH}$ waardoor de beschikbare ijzerconcentratie in gronden met een hoge $\mathrm{pH}$ beperkend kan zijn. Daarentegen komt op gronden met een neutrale of lage zuurgraad geen ijzerdeficiëntie van de bodem voor. Zodoende vormt ijzer-deficiëntie een omvangrijk probleem in aride en semi-aride gebieden met kalkrijke gronden. Circa $30 \%$ van alle bodems in de wereld zijn kalkrijk en daarmee potentieel ijzer-deficiënt (Schenkeveld et al. 2010). Bij gronden met ijzer-deficiëntie is het totale ijzergehalte in de bodem toereikend, maar is er een tekort aan de hoeveelheid plant-beschikbaar ijzer.

Synthetische ijzerchelaten heffen het tekort aan ijzer op doordat deze producten gedurende lange tijd de ijzerconcentratie in het bodemvocht verhogen. Er zijn diverse chelaatvormen op de markt, elk met een specifieke bindingsconstante voor ijzer. De keuze voor het type chelaat hangt samen met de condities (met name pH) waaronder het product werkzaam moet zijn. Zo wordt Fe-DTPA veel gebruikt voor toepassingen in de tuinbouw bij een lage tot neutrale $\mathrm{pH}$, terwijl voor toepassing in alkalische gronden het stabielere Fe-HBED de voorkeur heeft.

Uit literatuuronderzoek komt naar voren dat er reeds in de jaren 70 en 80 onderzoek is gedaan naar gebruik van amorfe ijzerhydroxiden (ferryhydriet) ter voorkoming van ijzer chlorose in ijzer-deficiënte kalkrijke gronden. Hierbij worden positieve effecten op ijzeropname (Díaz et al. 2009; Green et al. 1998; Vempati and Loeppert, 1986) gerapporteerd, echter bij de interpretatie moet worden opgemerkt dat de gebruikte doseringen veelal extreem hoog (>100 mg Fe/kg) zijn en zodoende niet praktijkrelevant. Meer recent is onderzoek gedaan naar de mogelijkheden om humuszuren in te zetten als alternatief voor synthetische chelaten. Het overgrote deel van het beschikbare onderzoek is uitgevoerd door de universiteit van Udine (Italië). Deze groep heeft wateroplosbare humuszuren (WEHS) door middel van kationenomwisseling voorzien van ijzer (Fe-WEHS) . Dit product verhoogt de opname van ijzer door komkommerplanten bij de teelt in watercultuur, in vergelijking met een controlebehandeling zonder enige vorm van ijzer (Tomasi et al. 2012 en 2014). In een vergelijkbare proefopzet is eveneens aangetoond dat komkommerplanten amorf ijzerhydroxide als ijzerbron kunnen gebruiken (Colombo et al. 2012). De werkzaamheid van deze producten is echter uitsluitend getest in waterculturen waardoor de resultaten niet vertaald kunnen worden naar een toepassing in de volle grond. Kortom, op basis van de beschikbare literatuur is het niet bekend of amorfe ijzerhydroxiden, al dan niet in combinatie met humus/fulvozuren, de ijzeropname in ijzer-deficiënte gronden kunnen verhogen.

Om de perspectieven van het gebruik van ijzerslib als ijzermeststof te kunnen beoordelen, is allereerst behoefte aan inzicht in de samenstelling van ijzerslib en de wijze waarop dit materiaal zich gedraagt in de bodem. Om deze kennisvragen te beantwoorden, heeft Wageningen Universiteit i.s.m. Wageningen Environmental Research (Alterra) een reeks analyses en laboratoriumtesten uitgevoerd waarvan de resultaten worden beschreven in dit rapport. 


\section{Materiaal en Methoden}

\subsection{Materialen}

\section{Materialen - 2015}

IJzerspoelwater van vijf locaties is door Vitens bemonsterd: Spannenburg, Hammerflier, Engelse Werk, St. Jansklooster en Wierden. Het betreft het niet-ingedikte spoelwater, dus zonder polyelectroliet. Daarnaast is ingedikt ijzerslib (met poly-electroliet) bemonsterd op Spannenburg en Hammerflier. Verder is een 2L-jerrycan met HumVi (regeneraat anionenwisselaar) geleverd door Vitens. De jerrycans met slib zijn in juni 2015 geleverd en in de koelcel bewaard tot moment van analyse.

\section{Materialen - 2016}

IJzerwater en ijzerslib van drie locaties (Tabel 2.1) zijn in mei 2016 aangeleverd. IJzerwater is een waterige suspensie. Het ijzerslib is bemonsterd uit een grote verzameltank en bevat zowel spoelwater van het eerste als het tweede filter, waardoor het kalkgehalte hiervan mogelijk hoger is dan van ijzerwater. Het onderzochte ijzerslib is door additie van poly-electroliet ingedikt, waardoor een steekvast product ontstaat.

Het ijzerwater is op het lab verder ingedikt door het slib uit te laten zakken en het bovenstaande heldere water af te zuigen. Dit is niet gedaan bij slib van Hammerflier, omdat dit ijzerwater reeds een vrij hoog drogestofgehalte had en het bovenstaande water troebel was. Alle monsters zijn gedurende de looptijd van het project bewaard in de koelcel $\left(5^{\circ} \mathrm{C}\right)$. IJzerwater van Hammerflier is later aangeleverd en daarom niet bij alle analyses meegenomen. HumVi is geleverd in september 2015 en sindsdien in een koeling bewaard.

Verder zijn twee ijzermeststoffen van AkzoNobel (contact: Levi Bin) opgevraagd en in het onderzoek meegenomen ter vergelijking (Tabel 2.2).

Tabel 2.1 Bemonsteringslocaties ijzerwater en ijzerslib in 2016.

\begin{tabular}{ll} 
Locatie & Opmerking \\
Spannenburg & IJzerwater (op lab ingedikt) en ijzerslib \\
\hline St. Jansklooster & IJzerwater (op lab ingedikt) en ijzerslib \\
\hline Hammerflier & IJzerwater (niet ingedikt) en ijzerslib \\
\hline
\end{tabular}

Tabel 2.2 Commerciële ijzerchelaatmeststoffen.

\begin{tabular}{lllll} 
Naam & Chelaat & Fe-gehalte & pH in 1\% oplossing & Formule \\
Dissolvine D-Fe-11 & DTPA & $11 \%$ & 2.7 & (DTPA.Fe)H Na \\
\hline Bolikel XP & HBED & $6.1 \%$ & 7 & (HBED.Fe)K \\
\hline
\end{tabular}




\section{$2.2 \quad$ Methoden}

Alle laboratoriumexperimenten en analyses zijn uitgevoerd door het Chemisch Biologisch Laboratorium Bodem (CBLB), onderdeel van de leerstoelgroep Bodemscheikunde van Wageningen University, tenzij anders vermeld. Het laboratorium heeft een RvA-accreditatie voor testlaboratoria (L342).

\subsubsection{Karakterisatie ijzerslib en HumVi (2015)}

\section{Voorbehandeling}

Voor zover mogelijk zijn alle bepalingen uitgevoerd op de suspensies, omdat indrogen de fysische eigenschappen van het materiaal kan veranderen. Om een representatief submonster te nemen, zijn de jerrycans goed geschud vóór het nemen van de submonsters. Het organische-stofgehalte en kalkgehalte kunnen alleen bepaald worden op een vaste stof. Hiervoor zijn de suspensies ingedampt in een oven bij $70^{\circ} \mathrm{C}$. De vaste stof verkregen na indampen, is fijngemalen door middel van colloïdmalen. Om metingen op suspensies en vaste stof te kunnen omrekenen, is het drogestofgehalte bepaald (bij $70^{\circ} \mathrm{C}$ ).

\section{Samenstelling ijzerwater/slib}

De gehalten van $\mathrm{CaCO}_{3}$, organisch $\mathrm{C}$ en van metalen zijn bepaald op het gedroogde materiaal. Het $\mathrm{CaCO}_{3}$ gehalte is volumetrisch bepaald na het oplossen van $\mathrm{CaCO}_{3}$ met $\mathrm{HCl}$. Het organisch koolstof gehalte is bepaald met behulp van een LECO $\mathrm{C} / \mathrm{N}$ analyzer na het verwijderen van $\mathrm{CaCO}_{3}$ met behulp van zuur. Voor het bepalen van de gehalten van de verschillende elementen is een Aqua Regiadestructie uitgevoerd. Voor het ijzerspoelwater is deze destructie op de suspensie uitgevoerd. Voor het ijzerslib is de destructie uitgevoerd op het gedroogde materiaal. De concentraties van de elementen in de extractieoplossing zijn vervolgens bepaald d.m.v. ICP-AES ( $\mathrm{Al}, \mathrm{Ca}, \mathrm{Cr}, \mathrm{Cu}, \mathrm{Fe}, \mathrm{K}, \mathrm{Mg}, \mathrm{Mn}, \mathrm{Na}, \mathrm{Ni}, \mathrm{P}$, $\mathrm{S}, \mathrm{Zn}$ en $\mathrm{Si}$ ). Voor het bepalen van $\mathrm{Si}$ is de ICP-AES-meting herhaald met een aangepaste opstelling om vervuiling van het monster met Si uit glazen onderdelen van de ICP-AES te voorkomen.

\section{Samenstelling HumVi}

De $\mathrm{pH}$ van het HumVi fulvozuur is bepaald. De fracties humuszuur, fulvozuur en hydrofiele zuren zijn bepaald volgens een standaard methode (Van Zomeren and Comans, 2007) nadat het monster 1000x is verdund. Humuszuren zijn gedefinieerd als de fractie welke neerslaat bij aanzuren tot $\mathrm{pH} 1$, terwijl fulvozuren en hydrofiele zuren onder deze omstandigheden in oplossing blijven. Het onderscheid tussen fulvozuren en hydrofiele zuren is gemaakt door fulvozuren te laten adsorberen aan DAX resin.

\section{Deeltjesgrootte en zèta-potentiaal van ijzerwater/slib}

Bij aanvang van dit onderzoek was het onduidelijk welke methode geschikt zou zijn om de deeltjesgrootte van het ijzerslib te bepalen vanwege onzekerheid over de ordegrootte van de deeltjes en onzekerheid over het optreden van artefacten door monstervoorbewerking. Er zijn daarom drie meetmethoden voor het bepalen van de deeltjesgrootte van colloïden in het slib voorgesteld: de pipetmethode, de Coulter-teller en met behulp van Asymmetric Flow Field Flow Fractionation (AF4).

De pipetmethode wordt in de bodemkunde gebruikt voor het bepalen van het klei- en siltgehalte in bodemmonsters. In deze methode wordt de deeltjesgrootte afgeleid van de bezinksnelheid van deeltjes. Uit een eerste test bleek echter dat deze methode niet geschikt is voor ijzerslib. De standaard voorbewerking, waarbij beoogd wordt de aggregaten te dispergeren, leidt tot het oplossen van de Fe-deeltjes. Zonder deze voorbewerking kan de bezinksnelheid niet worden omgerekend naar een deeltjesgrootte, omdat de aggregaten de neiging hebben om te 'drijven'.

In de Coulter-teller (LS 230 Fluid Module) wordt de deeltjesgrootte van colloïden bepaald op basis van light-scattering. Deze techniek is nauwkeurig en snel en er is géén voorbehandeling noodzakelijk. De suspensies zijn voor de bepaling in een ultrasoon bad geplaatst om aggregaten te dispergeren. Vervolgens zijn de suspensies verdund tot een concentratie waarbij de Coulter-teller afzonderlijke deeltjes kan detecteren.

Bepaling 1: 30 juni 2015 (waterijzer en slib)

Bepaling 2: 24 aug. 2015 (waterijzer, slib en HumiV-Fe monsters). 
De AF4 is een methode die uitsluitend geschikt is voor het karakteristeren van nanodeeltjes $(<0.5 \mu \mathrm{m})$. Uit de uitslagen van de Coulter-teller is gebleken dat de grootte van de colloïden in het ijzerspoelwater/slib ver buiten deze range valt.

De zèta-potentiaal, oftewel de oppervlaktelading, van de colloïden in het ijzerspoelwater/slib is bepaald op basis van elektroforese door middel van een zètasizer. Hierin wordt de snelheid waarmee colloïden zich verplaatsen (in oplossing) ten opzichte van een positief en een negatief geladen elektrode gemeten.

Het ijzerslib is 10 maal verdund voor het bepalen van de zèta-potentiaal om uitzakken zoveel mogelijk te voorkomen. De zèta-potentiaal is tevens bepaald voor de HumVi-spoelwater en HumVi-slib mengsels. Metingen zijn uitgevoerd door het lab van de leerstoelgroep Physical Chemistry and Soft Matter.

\section{IJzerconcentratie in de waterfase met of zonder HumVi}

Suspensies zijn gecentrifugeerd en daarna gefilterd over een 0,45- $\mu \mathrm{m}$ membraanfilter. De $\mathrm{pH}$ en concentraties van opgeloste elementen ( $\mathrm{Fe}, \mathrm{Al}, \mathrm{Ca}, \mathrm{Mg}, \mathrm{Mn}$ en $\mathrm{P}$ ) zijn gemeten in de gefiltreerde oplossing. Wateroplosbare concentraties geven een schatting van de beschikbaarheid van elementen voor plantopname.

\subsubsection{Laboratoriumtesten (2016)}

\section{Samenstelling ijzerslib}

De chemische samenstelling van het ijzerwater en ijzerslib (geleverd in 2016) is bepaald na destructie met Aqua Regia (magnetron-destructie), uitgevoerd op de vloeibare monsters. De samenstelling van het destruaat is geanalyseerd door middel van ICP-AES. Analyse van zink was niet mogelijk vanwege storingen op de meting door de afwijkende matrix. Het organische koolstofgehalte is bepaald op gedroogde monsters $\left(105^{\circ} \mathrm{C}\right.$ ) met behulp van een LECO $\mathrm{C} / \mathrm{N}$ analyzer na het verwijderen van $\mathrm{CaCO}_{3}$ met behulp van zuur. Het Fe-DTPA gehalte in ijzerslib en in de grondmonsters is bepaald volgens een standaardmethode (Lindsay and Norvell, 1978).

\section{Samenstelling supernatant na HumVi-additie aan ijzerslib/water}

HumVi, met een concentratie van $125 \mathrm{~g} / \mathrm{L}$, is in doseringen van $0 ; 2,5 ; 5 ; 12,5$; en $25 \%(\mathrm{v} / \mathrm{v}$ ) gemengd met ijzerspoelwater en ijzerslib. De mengsels zijn vervolgens op een lage snelheid gedurende twee uur geschud en daarna gecentrifugeerd (10 min, $3000 \mathrm{rpm}$ ). Het supernatant is afgegoten en bewaard voor analyse. Het effect van schudtijd op de Fe-concentratie in het supernatant is bepaald in een aanvullende test voor de behandelingen met een HumVi-dosering van 0, 12;5 en $25 \%$. Voor deze serie monsters is het supernatant geanalyseerd na 24 en 96 uur schudden.

In het supernatant van bovenstaande testen is zowel de totale ijzerconcentratie (inclusief colloïden) als de 'opgeloste' ijzerconcentratie $(<0,45 \mu \mathrm{m})$ bepaald. IJzer-totaal is bepaald op niet-gefiltreerde monsters en na 100x verdunning met demiwater. De 'opgeloste' Fe-concentratie is bepaald na filtratie over 0,45 $\mu \mathrm{m}$. Om de monsters te kunnen filtreren, zijn de monsters verdund met demiwater. Om het effect van verdunning op de ijzerconcentratie na filtratie te bepalen, is de filtratie uitgevoerd na 50x en 500x verdunning. Analyse van ijzer (en $\mathrm{P}, \mathrm{Zn}, \mathrm{Cu}$ ) is uitgevoerd met behulp van ICP-AES. Concentraties organisch koolstof (TOC) zijn bepaald door oxidatie en meting van de $\mathrm{CO}_{2}$-concentratie met een Segmented Flow Analyser (SFA).

\subsubsection{Testen stabiliteit Fe-HumVi in bodem}

De werking van ijzerchelaatmeststoffen is gebaseerd op het feit dat deze meststoffen na toevoeging aan de bodem in oplossing blijven waardoor deze via het water naar de plantenwortel getransporteerd worden. Zodoende kan verwacht worden dat de werking van een alternatieve ijzermeststof op basis van ijzerslib en humuszuur mede samenhangt met de mate waarin dit product stabiel is in de bodemoplossing (i.e. in oplossing blijft). Om dit te testen, is Fe-HumVi-product aan diverse grondsuspensies toegevoegd waarna het verloop in de ijzerconcentratie in het vocht is bepaald. Er zijn verschillende samenstellingen van een Fe-HumVi-product gemaakt. 


\section{Test 1}

De stabiliteit van Fe-HumVi na additie aan grond is getest voor vier Fe-HumVi-producten en vergeleken met twee ijzerchelaatmeststoffen. Daarnaast zijn een behandeling met alleen HumViadditie en een controlebehandeling met demiwater meegenomen. De samenstelling van de producten is opgenomen in Tabel 2.3. De Fe-HumVi-producten zijn voor aanvang van de proef verdund met demiwater tot een ijzerconcentratie $(<0,45 \mu \mathrm{m})$ van $500 \mathrm{mg} / \mathrm{L}$, zodat bij iedere behandeling een gelijke hoeveelheid ijzer wordt gedoseerd. (NB De TOC-dosering varieert wel tussen de behandelingen, omdat de Fe/TOC-verhouding varieert tussen de Fe-HumVi-producten.)

Er zijn vier gronden geselecteerd (zie paragraaf 3.3.1). Daarvan zijn suspensies gemaakt van $8 \mathrm{~g}$ grond met $80 \mathrm{ml}$ water $(0,1 \mathrm{~kg} / \mathrm{L})$. Hieraan zijn producten P1-P7 of demiwater toegevoegd tot een concentratie van $5 \mathrm{mg} \mathrm{Fe} / \mathrm{L}$ in het vocht. Dit resulteert in 32 behandelingen, uitgevoerd in enkelvoud. $\mathrm{Na}$ 3, 14 en 31 dagen is een submonster genomen dat na centrifugeren en filtreren is geanalyseerd op $\mathrm{Fe}, \mathrm{Ca}, \mathrm{Cu}, \mathrm{K}, \mathrm{Mg}, \mathrm{P}$ en $\mathrm{Zn}$. Metingen van elementen zijn uitgevoerd op de ICP-AES in aangezuurde monsters. In de monsters van dag 31 is ook TOC gemeten.

Tabel 2.3 Overzicht en samenstelling geteste ijzer-HumVi-producten en ijzerchelaatmeststoffen.

\begin{tabular}{|c|c|c|c|}
\hline Nr. & Omschrijving & $\begin{array}{l}F e_{t}<0,45 \mu m^{a} \\
(m g / I)\end{array}$ & $\begin{array}{l}\text { TOC } \\
(\mathrm{mg} / \mathrm{I})\end{array}$ \\
\hline $\mathrm{P} 1^{\mathrm{b}}$ & Supernatant o.b.v. ijzerslib St. Jansklooster $+25 \%$ HumVi & 1885 & 33500 \\
\hline $\mathrm{P}^{\mathrm{b}}$ & Supernatant o.b.v. ijzerslib Hammerflier $+12.5 \%$ HumVi & 6300 & 16200 \\
\hline $\mathrm{P} 4^{\mathrm{b}}$ & Supernatant o.b.v. ijzerslib Hammerflier $+25 \%$ HumVi & 5150 & 33350 \\
\hline P6 & Bolikel XP Fe-HBED meststof & 500 & 335 \\
\hline P7 & HumVi $(12,5 \%)$ & 17.5 & 16775 \\
\hline P8 & Demiwater & $<$ d.l. & $<$ d.l. \\
\hline
\end{tabular}

\section{Test 2}

Om het effect van bodemeigenschappen op de stabiliteit van ijzer verder te onderzoeken, is er een schudtest uitgevoerd met één Fe-HumVi-product (product P2 in Tabel 2.3) en zes gronden. De bodemeigenschappen zijn opgenomen in Tabel 3.13.

Aan $40 \mathrm{~g}$ grond is $80 \mathrm{ml}$ water toegevoegd en vervolgens de Fe-HumVi. In vergelijking met test 1 is nu een aanzienlijk hogere grond-vloeistofverhouding gehanteerd $(0,5 \mathrm{~kg} / \mathrm{l})$. Het is om praktische redenen noodzakelijk om zo veel water toe te voegen totdat een slurry ontstaat, zodat het mogelijk is om water af te centrifugeren en te analyseren op Fe. Het watergehalte van de bodem tijdens de proef is daarmee circa tienmaal hoger dan bij veldvochtige grond. De test is uitgevoerd met twee doseringen van 3,7 en 5,5 mg Fe/L bodemvocht. Na 14 dagen zijn de bodemmonsters gecentrifugeerd (bij $3000 \mathrm{rpm}$ ) en is het bovenstaande water afgegoten, gefiltreerd en geanalyseerd op $\mathrm{Fe}, \mathrm{Ca}, \mathrm{Mg}$, $\mathrm{Na}$, $\mathrm{K}$ en TOC. 


\section{Resultaten}

Achtereenvolgens worden, in chronologische volgorde, de resultaten van de karakterisatie van ijzerwater/slib (2015) en de laboratoriumproeven (2016) beschreven.

\subsection{Karakterisatie ijzerspoelwater en ijzerslib}

\subsubsection{Samenstelling}

De resultaten van de analyses van de chemische samenstelling van het ijzerspoelwater en ijzerslib staan in Tabel 3.1 en 3.2.

Op alle onderzochte locaties heeft het ijzerspoelwater een neutrale tot licht-basische $\mathrm{pH}$. Het kalkgehalte is over het algemeen hoog (10-30\%), behalve in Wierden, waar het ijzerspoelwater vrijwel kalkloos is. De afwezigheid van kalk in het spoelwater in Wierden komt overeen met de lagere $\mathrm{pH}(7,2)$ op deze locatie. Op de andere locaties wordt de $\mathrm{pH}$ gebufferd door het kalk, waardoor er weinig variatie is in $\mathrm{pH}(7,7-8,1)$. Het kalkgehalte van het ijzerslib is beduidend lager dan van ijzerwater. Waarschijnlijk zijn de ijzerwatermonsters door temporele variatie in de samenstelling niet representatief voor de gemiddelde samenstelling van het ijzerslib.

Het organische koolstofgehalte varieert tussen 44 en $65 \mathrm{~g} / \mathrm{kg}$, wat overeenkomt met circa 8,8-13\% organische stof. Hierbij is aangenomen dat $1 \mathrm{~g}$ organische stof $0,5 \mathrm{~g}$ koolstof bevat. Het hoge organische-stofgehalte wijst erop dat ijzerslib fungeert als een filter voor organische zuren. In het ijzerslib zijn lage gehalten aan zink, koper en nikkel aangetroffen (Tabel 2). In het ijzerwater waren de concentraties van deze metalen lager dan de detectiegrens (< d.I.).

Tabel 3.1 Samenstelling ijzerspoelwater in $\mathrm{mg} / \mathrm{L}$ product (monsters 2015)

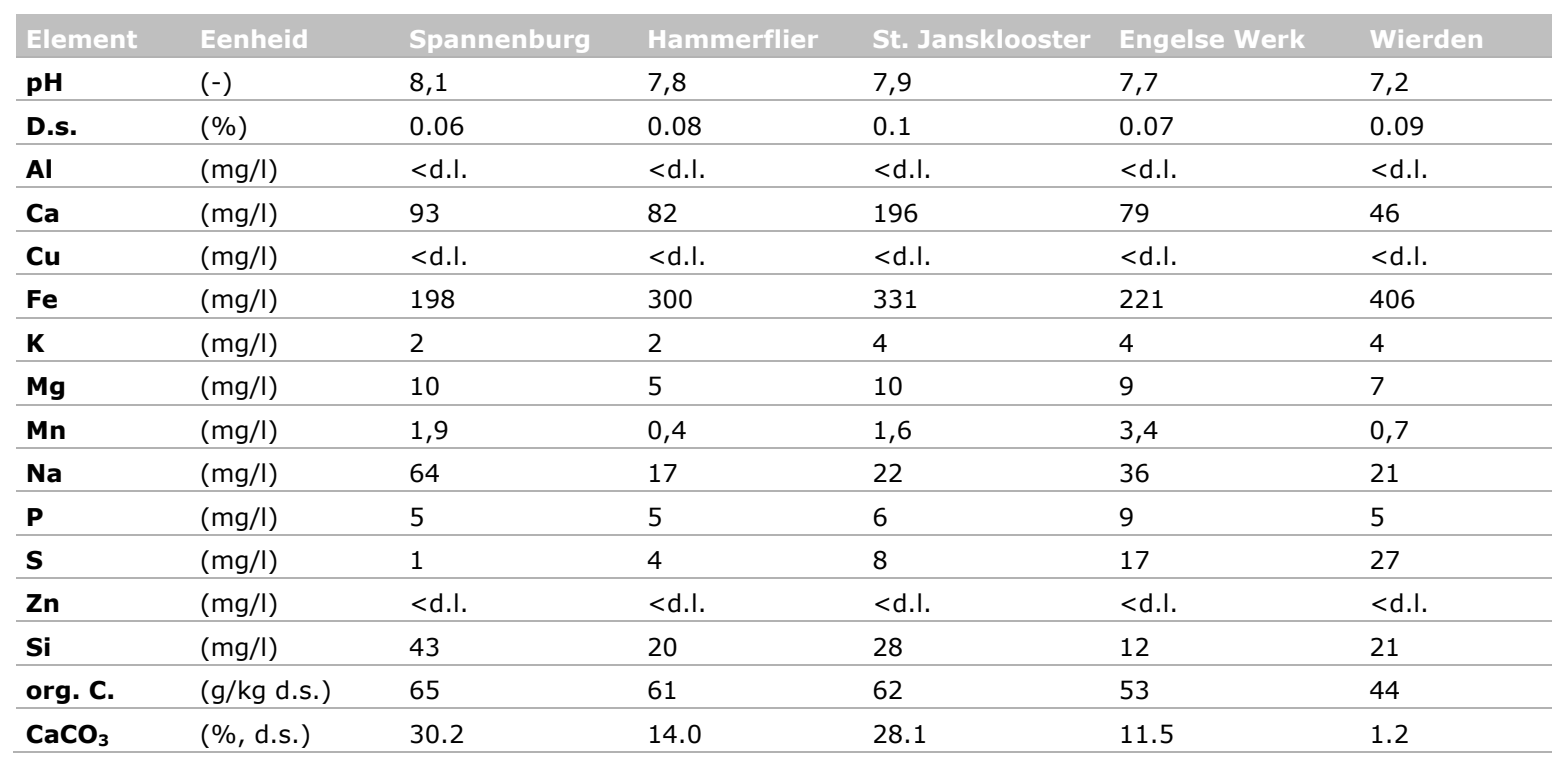

a Elementen zijn bepaald na destructie van de suspensies met Aqua Regia. Het organische koolstof- (org. C) en kalkgehalte $\left(\mathrm{CaCO}_{3}\right)$ zijn uitgedrukt op basis van droge stof. Het drogestofgehalte is bepaald bij $70^{\circ} \mathrm{C}$. 
Tabel 3.2 Samenstelling ijzerslib op basis van droge stof (monsters 2015).

\begin{tabular}{|c|c|c|c|}
\hline \multicolumn{2}{|c|}{ Element } & $\begin{array}{l}\text { Spannenburg - slib } \\
8,00\end{array}$ & $\begin{array}{l}\text { Hammerfiler - slib } \\
6,94\end{array}$ \\
\hline D.s. & $(\%)$ & 1.1 & 6.7 \\
\hline $\mathrm{Ca}$ & $(\mathrm{g} / \mathrm{kg})$ & 45 & 20 \\
\hline $\mathbf{C r}$ & $(\mathrm{mg} / \mathrm{kg})$ & 7,6 & 15,5 \\
\hline $\mathbf{F e}$ & $(\mathrm{g} / \mathrm{kg})$ & 294 & 412 \\
\hline K & $(\mathrm{mg} / \mathrm{kg})$ & 255 & 103 \\
\hline Mg & $(\mathrm{mg} / \mathrm{kg})$ & 1497 & 303 \\
\hline Mn & $(\mathrm{mg} / \mathrm{kg})$ & 4405 & 754 \\
\hline $\mathbf{s}$ & $(\mathrm{mg} / \mathrm{kg})$ & 756 & 786 \\
\hline $\mathbf{Z n}$ & $(\mathrm{mg} / \mathrm{kg})$ & 5 & 10 \\
\hline Si & $(\mathrm{mg} / \mathrm{kg})$ & 92,5 & 141 \\
\hline OC & $(\mathrm{g} / \mathrm{kg})$ & 43 & 54 \\
\hline $\mathrm{CaCO}_{3}$ & $(\%)$ & 4,9 & 0,8 \\
\hline
\end{tabular}

Op basis van de elementaire samenstelling kan de mineralogische samenstelling geschat worden. Hieruit blijkt dat ijzerwater en ijzerslib voor $46-76 \%$ bestaan uit ijzerhydroxiden (FeOOH, amorf ijzerhydroxide; verder in de tekst aangeduid als ijzerhydroxide). Het overige deel bestaat uit kalk, organische stof en zanddeeltjes (Tabel 3.3).

Tabel 3.3 Geschat aandeel van mineralen en organische stof in ijzerspoelwater in \% van het drogestofgehalte ${ }^{a}$.

\begin{tabular}{|c|c|c|c|c|c|c|c|}
\hline Mineraal & Spannenburg & Hammerflier & St. Janskl. & Engelse $W$. & Wierden & Span-slib & Hamm-slib \\
\hline $\mathrm{FeOOH}$ & $53 \%$ & $61 \%$ & $46 \%$ & $51 \%$ & $76 \%$ & $47 \%$ & $66 \%$ \\
\hline $\mathrm{CaCO}_{3}$ & $30 \%$ & $14 \%$ & $28 \%$ & $12 \%$ & $1 \%$ & $5 \%$ & $1 \%$ \\
\hline $\mathrm{SiO}_{2}$ & $16 \%$ & $5 \%$ & $5 \%$ & $4 \%$ & $5 \%$ & $0 \%$ & $0 \%$ \\
\hline $\mathrm{Na}$ & $11 \%$ & $2 \%$ & $2 \%$ & $5 \%$ & $2 \%$ & $0 \%$ & $0 \%$ \\
\hline
\end{tabular}

De molaire ratio tussen fosfor en ijzer $(\mathrm{P} / \mathrm{Fe})$ en organisch koolstof en ijzer $(\mathrm{C} / \mathrm{Fe})$ zijn gegeven in Tabel 3.4. De P/Fe-ratio varieert tussen 0,02 en $0,07 \mathrm{~mol} / \mathrm{mol}$.

De molaire C/Fe-ratio varieert tussen 0,4-1,0 en is daarmee zeer hoog, wat erop wijst dat de Feoxiden-deeltjes waarschijnlijk volledig bedekt zijn met organische stof. Een dergelijk hoge C/Fe ratio kan alleen behaald worden wanneer de ijzerdeeltjes zeer klein zijn. Kleinere deeltjes hebben immers een groter specifiek oppervlak $\left(\mathrm{m}^{2} / \mathrm{gram}\right)$. Uit schattingen op basis van literatuur kan afgeleid worden dat de ijzerdeeltjes bij deze C/Fe ratio kleiner zijn dan 10 nanometer (Regelink, 2014). NB In latere testen is de TOC-concentratie in de waterfase (na centrifugeren en filtratie) bepaald, die varieert van 4-20 mg/L. Hieruit blijkt dat organisch koolstof in ijzerslib voor meer dan $95 \%$ gebonden is aan ijzerslib.

Tabel 3.4 Molaire ratio fosfaat/ijzer (P/Fe) en organisch koolstof/ijzer (C/Fe) in ijzerwater en ijzerslib.

\begin{tabular}{lcccccccc} 
Ratio (-) & Spannenburg & Hammerflier & St. Jansklooster & Engelse Werk & Wierden & Span-slib & Hamm-slib \\
\hline P/Fe (-) & 0,04 & 0,03 & 0,03 & 0,07 & 0,02 & 0,05 & 0,03 \\
\hline C/Fe (-) & 0,9 & 0,8 & 1,0 & 0,8 & 0,4 & 0,7 & 0,6 \\
\hline
\end{tabular}




\subsubsection{Deeltjesgrootte en oppervlaktespanning}

De deeltjesgrootte en de zèta-potentiaal gemeten in het ijzerslib en ijzerspoelwater zijn opgenomen in tabellen 3.5 en 3.6. De deeltjesgrootteverdeling is eveneens weergegeven in Figuren 3.5-3.7.

De zèta-potentiaal is een maat voor de oppervlaktelading van colloïden en is een indicator voor de colloïdale stabiliteit van deeltjes. Deeltjes met sterk sterke negatieve zèta-potentiaal zullen elkaar afstoten waardoor zij in oplossing blijven. Deeltjes met weinig negatieve tot neutrale zèta-potentiaal zullen coaguleren en uitzakken. Kenmerkend voor ijzerhydroxiden is dat ze bij een neutrale $\mathrm{pH}$ een positieve zèta-potentiaal hebben. De colloïden in het ijzerwater/slib hebben echter een negatieve zètapotentiaal, wat verklaard kan worden door de adsorptie van (negatief geladen) fulvozuren op de ijzerhydroxiden. Een spanning van $-20 \mathrm{mV}$ is echter niet sterk negatief, waardoor verwacht wordt dat de deeltjes na verloop van tijd wel zullen coaguleren en uitzakken. Opvallend is dat de zèta-potentiaal in ijzerwater vergelijkbaar is met die van ijzerslib, terwijl verwacht zou worden dat de additie van poly-electroliet aan het ijzerslib zou leiden tot neutralisatie van de oppervlaktelading. Na additie van HumVi neemt de oppervlaktespanning af tot circa $-50 \mathrm{mV}$. Dit geeft aan dat HumVi een coagulatie van de ijzerdeeltjes verhindert; m.a.w. na additie van HumVi zullen ijzerdeeltjes beter in oplossing blijven, omdat het HumVi een stabiliserende werking heeft op de ijzercolloïden.

Tabel 3.5 Deeltjesgrootteverdeling (in procenten) van colloïden in ijzerwater/ijzerslib bepaald met behulp van een Coulter-teller.

\begin{tabular}{llllllll} 
& Spannenburg & Hammerflier & St. Janskl. & Engelse W. Wierden & Span-slib Hamm-slib \\
\hline Fractie< $2 \mathbf{~} \mathbf{m}$ & 17 & 28 & 5 & 19 & 17 & 4 & 3 \\
\hline Fractie< $\mathbf{1 6} \mathbf{~} \mathbf{m}$ & 89 & 94 & 69 & 86 & 69 & 51 & 38 \\
\hline Fractie< $\mathbf{5 0} \mathbf{~} \mathbf{m}$ & 100 & 100 & 99 & 100 & 100 & 90 & 92 \\
\hline
\end{tabular}

Tabel 3.6 Zèta-potentiaal (oppervlaktelading) van colloïden in ijzerwater/ijzerslib.

\begin{tabular}{|c|c|c|c|}
\hline Locatie & Type & HumVi & $\begin{array}{l}\text { Zèta-potentiaal } \\
(\mathrm{mV})\end{array}$ \\
\hline Spannenburg & ijzerwater & & -21 \\
\hline St. Jansklooster & ijzerwater & & -15 \\
\hline Engelse Werk & ijzerwater & & -25 \\
\hline Hammerflier & ijzerslib & & -22 \\
\hline Spannenburg & ijzerwater & $5 \%$ & -48 \\
\hline Spannenburg & ijzerslib & $5 \%$ & -31 \\
\hline Hammerflier & ijzerwater & $5 \%$ & -51 \\
\hline
\end{tabular}

Bepalingen van de deeltjesgrootte (Tabel 3.5) tonen aan dat het overgrote deel van de colloïden in ijzerwater kleiner is dan 16 micrometer. IJzerslib kenmerkt zich door grotere deeltjes, wat duidt op coagulatie. De grootte van de ijzercolloïden komt overeen met die van silt en fijn zand en is daarmee groter dan verwacht werd op basis van de hoge C/Fe-ratio, die duidt op aanwezigheid van nanodeeltjes. Waarschijnlijk bestaat ijzerslib uit nanodeeltjes die zijn samengeklonterd tot deeltjes van enkele tientallen micrometers groot.

De bepaling met de Coulter-teller is na 3 maanden herhaald om het effect van tijd op de deeltjesgrootte te kunnen beoordelen (Figuur 3.1). Hieruit blijkt dat de deeltjesgrootte niet verandert gedurende twee maanden na opslag in een koelcel. 


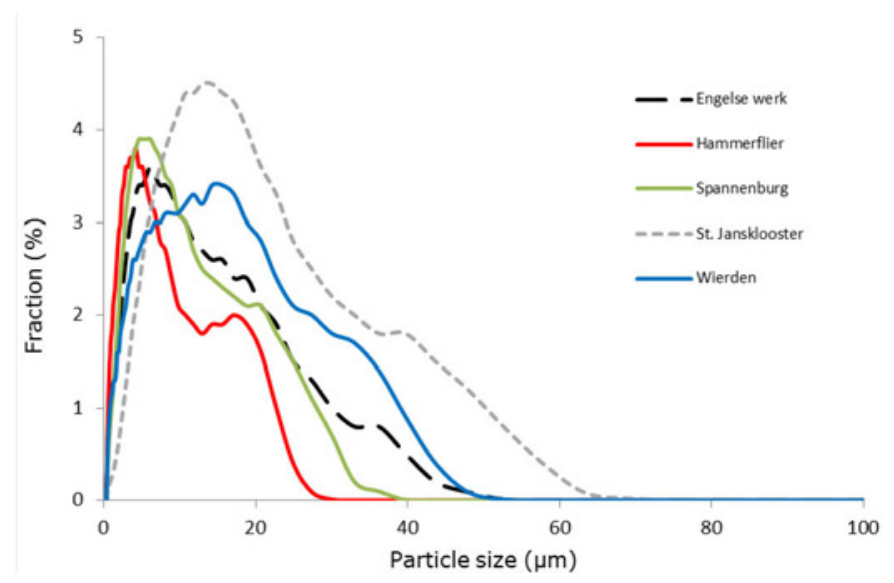

Figuur 3.1 Deeltjesgrootte (in $\mu m$ ) van colloïden in ijzerspoelwater.

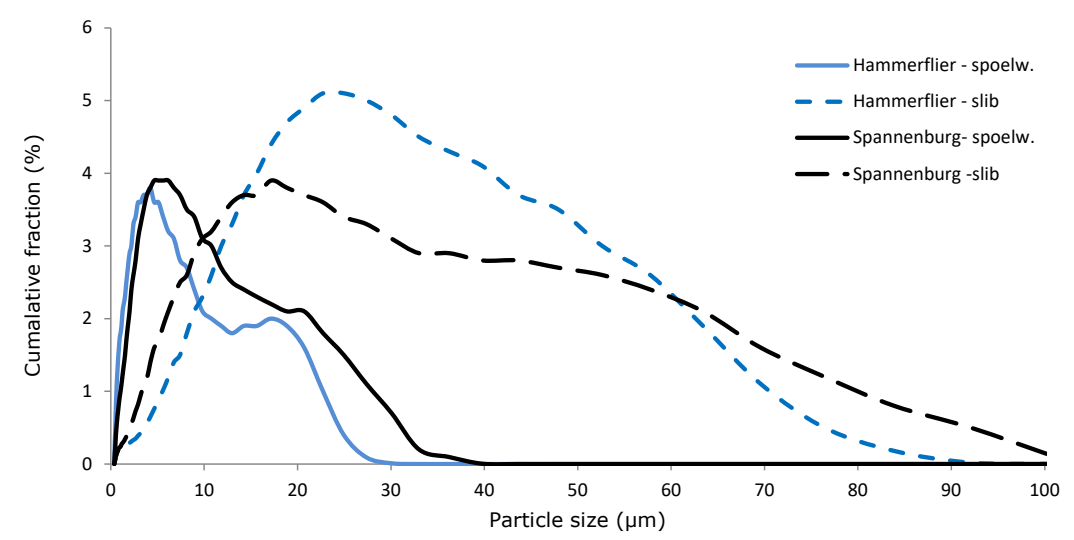

Figuur 3.2 Deeltjesgrootte (in $\mu \mathrm{m}$ ) van colloïden in ijzerspoelwater en ijzerslib (met polyelectroliet).

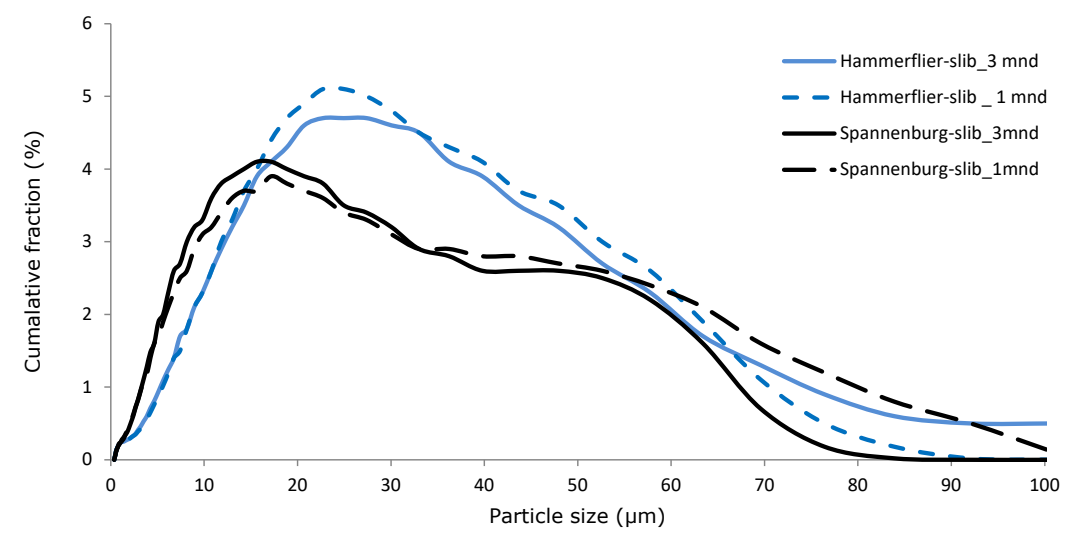

Figuur 3.3 Deeltjesgrootte (in $\mu \mathrm{m}$ ) van colloïden in ijzerslib (met poly-electroliet) na 1 en 3 maanden opslag.

\subsubsection{Samenstelling HumVi}

Het onverdunde HumVi product bevat $125 \mathrm{~g} / \mathrm{l}$ TOC en heeft een zeer hoog natriumgehalte (42 g/l) (Tabel 3.7). Het hoge natriumgehalte ontstaat doordat de anionenwisselaar op het drinkwaterbedrijf geregenereerd wordt met $\mathrm{NaCl}$-zout. Doordat in de anionenwisselaar de organische zuren op basis van lading gescheiden worden, vindt ook een scheiding plaats van kationen waarbij tweewaardige kationen preferent in de waterfase blijven en eenwaardige kationen aan het HumVi-product adsorberen. De organische zuren in het HumVi-product bestaan grotendeels uit fulvozuren: deze zijn goed oplosbaar, maar kunnen wel adsorberen aan Fe-oxiden. 
Tabel 3.7 Samenstelling van HumVi op productbasis.

\begin{tabular}{ll} 
Parameter & Hum Vi \\
\hline TOC $(\mathrm{g} / \mathrm{l})$ & 125 \\
\hline Humuszuur (\% van TOC) & 2 \\
\hline Fulvozuur (\%) & 84 \\
\hline Hydrofiele zuren $\%)$ & 13 \\
\hline $\mathrm{pH}$ & 8,4 \\
\hline $\mathrm{Ca}(\mathrm{mg} / \mathrm{l})$ & 717 \\
\hline $\mathrm{Fe}(\mathrm{mg} / \mathrm{l})$ & 12 \\
\hline $\mathrm{Mn}(\mathrm{mg} / \mathrm{l})$ & 0,8 \\
\hline $\mathrm{Na}(\mathrm{mg} / \mathrm{l})$ & 3,7 \\
\hline
\end{tabular}

\subsubsection{Samenstelling van de waterfase van ijzerslib met en zonder HumVi}

De samenstelling van de waterfase na filtratie is bepaald om een indicatie te krijgen van het aandeel goed oplosbaar ijzer. Het ijzer in deze fractie kan aanwezig zijn als opgelost ijzer $\left(\mathrm{Fe}^{3+}\right)$, ijzer gecomplexeerd aan fulvozuur (Fe ${ }^{3+}$-DOC) en in de vorm van Fe-colloïden.

Uit de analyses (Tabel 3.8) blijkt dat er nagenoeg géén ijzer aanwezig is in de waterfase van het ijzerslib. Dit betekent dat ijzer volledig aanwezig is in de vorm van ijzerhydroxidedeeltjes die met centrifugeren en filtreren uit de waterfase verwijderd worden.

De waterfase van het slib is tevens geanalyseerd na additie van 5 en $10 \%$ HumVi (volumebasis, Tabel 3.9). Hieruit blijkt dat de ijzerconcentratie in de waterfase na additie van HumVi toeneemt van $0 \mathrm{mg} / \mathrm{l}$ naar 50-300 mg/L. Bij ijzerwater wordt 30-60\% van het ijzer na additie van HumVi teruggevonden in de waterfase. Voor ijzerslib ligt dit percentage wat lager. De meting is na 7 weken herhaald, waaruit blijkt dat ijzerconcentraties in de tijd niet wijzigen en het ijzer-HumVi-mengsel dus stabiel is. De opvallende toename in opgelost ijzer o.i.v. HumVi kon in eerste instantie niet goed verklaard worden. HumVi heeft namelijk net als ijzerslib een licht-basische $\mathrm{pH}$, waardoor additie van HumVi aan ijzerslib dus nauwelijks zal leiden tot een $\mathrm{pH}$-verandering. Eerst werd gedacht aan adsorptie van $\mathrm{Fe}^{3+}$ aan fulvozuren. Verdere analyses, beschreven in paragraaf 3.2, wijzen op het dispergeren van ijzerhydroxide deeltjes in de aanwezigheid van fulvozuur.

Tabel 3.8 Samenstelling van de waterfase van ijzerslib en ijzerwater na filtratie over 0,45 $\mu$ m.

\begin{tabular}{|c|c|c|c|c|c|c|c|c|}
\hline Elem. & Eenh. & Spannenb. & Hammerfl. & Spann. Slib & Hammer.Slib & St. Janskl & Engelse W. & Wierden \\
\hline pH & $(-)$ & 8,06 & 7,82 & 8,0 & 6,4 & 7,88 & 7,70 & 7,18 \\
\hline Al & $(\mathrm{mg} / \mathrm{l})$ & $<$ d.l. & $<$ d.I. & $<$ d.l. & $<$ d.l. & $<$ d.I. & $<$ d.l. & $<$ d.I. \\
\hline $\mathrm{Ca}$ & $(\mathrm{mg} / \mathrm{l})$ & 54,7 & 61,8 & 103 & 104 & 72,4 & 65,4 & 40,1 \\
\hline $\mathbf{F e}$ & $(\mathrm{mg} / \mathrm{l})$ & $<$ d.l. & 0,07 & 0,01 & 0,25 & 0,05 & $<$ d.l. & $<$ d.I. \\
\hline Mg & $(\mathrm{mg} / \mathrm{l})$ & 8,58 & 4,07 & 13,6 & 5,06 & 6,56 & 7,83 & 6,67 \\
\hline Mn & $(\mathrm{mg} / \mathrm{l})$ & $<$ d.l. & 0,059 & 1,75 & 1,42 & $<$ d.l. & 0,012 & 0,368 \\
\hline $\mathrm{Na}$ & $(\mathrm{mg} / \mathrm{l})$ & 62,6 & 16,7 & 64,3 & 19,6 & 20,8 & 35,4 & 20,7 \\
\hline $\mathbf{P}$ & $(\mathrm{mg} / \mathrm{l})$ & $<$ d.l. & $<$ d.l. & $<$ d.l. & $<$ d.l. & $<$ d.I. & $<$ d.l. & $<$ d.l. \\
\hline
\end{tabular}


Tabel 3.9 IJzerconcentratie in de waterfase $(<0,45 \mu \mathrm{m})$ van ijzerslib en ijzerwater met en zonder HumVi.

\begin{tabular}{|c|c|c|c|}
\hline HumVi ( $\%)$ & \multirow[t]{2}{*}{$\begin{array}{l}\text { HumVi } \\
\text { (g TOC/I) }\end{array}$} & \multicolumn{2}{|c|}{$\begin{array}{l}\text { 'opgelost } \mathrm{Fe}^{\prime}<0,45 \mu \mathrm{m} \\
(\mathrm{mg} / \mathrm{I})(\% \text { of total } \mathrm{Fe})\end{array}$} \\
\hline Spannenburg ijzerwater & & Na 24 uur & $\mathrm{Na} 7$ weken \\
\hline $0 \%$ & 0 & $0,04(0 \%)$ & n.m. \\
\hline $5 \%$ & 6,25 & $133(67 \%)$ & 171 \\
\hline $10 \%$ & 12,5 & $170(86 \%)$ & 181 \\
\hline \multicolumn{4}{|c|}{ Spannenburg ijzerslib } \\
\hline $0 \%$ & 0 & $0,01(0 \%)$ & n.m. \\
\hline $5 \%$ & 6,25 & $239(7 \%)$ & 125 \\
\hline $10 \%$ & 12,5 & $299(9 \%)$ & 224 \\
\hline \multicolumn{4}{|c|}{ Hammerflier ijzerwater } \\
\hline $0 \%$ & 0 & $0,07(0 \%)$ & n.m. \\
\hline $5 \%$ & 6,25 & $89(30 \%)$ & 107 \\
\hline $10 \%$ & 12,5 & $159(53 \%)$ & 165 \\
\hline \multicolumn{4}{|c|}{ Hammerflier ijzerslib } \\
\hline $0 \%$ & 0 & $0,25(0 \%)$ & n.m. \\
\hline $5 \%$ & 6,25 & $54(0 \%)$ & n.m. \\
\hline $10 \%$ & 12,5 & $164(1 \%)$ & n.m. \\
\hline
\end{tabular}




\subsection{Laboratoriumproeven ijzerslib en HumVi}

\subsubsection{Samenstelling ijzerwater en ijzerslib}

In 2016 zijn nieuwe batches ijzerspoelwater en ijzerslib aangeleverd. De samenstelling van deze monsters is opgenomen in Tabel 3.9. De concentraties fulvozuur, humuszuur en hydrofiele zuren in het HumVi-product zijn opgenomen in Tabel 3.6. Voor één spoelwatermonster is eveneens het FeDTPA gehalte bepaald, wat een gangbare extractie is voor bepaling van het plantbeschikbare ijzergehalte in de bodem. Hieruit blijkt dat het ijzer in ijzerspoelwater vrijwel niet extraheerbaar is met Fe-DTPA. Dat suggereert dat toediening van ijzerslib aan grond zeer waarschijnlijk geen substantiële verhoging van het Fe-DTPA-gehalte met zich mee zal brengen.

Tabel 3.10 Samenstelling ijzerwater, ijzerslib en HumVi (monsters 2016).

\begin{tabular}{|c|c|c|c|c|c|c|c|c|}
\hline & & \multicolumn{3}{|c|}{ IJzerspoelwater ${ }^{a}$} & \multicolumn{3}{|c|}{ IJzerslib } & \multirow[b]{2}{*}{ Humvi } \\
\hline & & Spannenb. & St. Jansk & Hammerfl. ${ }^{b}$ & Spannenb. & St. Jansk & Hammerfl. & \\
\hline Drogestof & $(\%)$ & 0,7 & 0,6 & & 4,1 & 3,6 & 8,1 & \\
\hline TOC & $(\mathbf{g} / \mathbf{k g})$ & 61 & 106 & 79 & 63 & 96 & 101 & \\
\hline pH & $(-)$ & 7,6 & 7,5 & & 7,8 & 6,8 & 6,4 & 8,3 \\
\hline $\mathbf{C a}$ & $(\mathrm{mg} / \mathrm{I})$ & 534 & 329 & n.m. & 2314 & 3396 & 1513 & 635 \\
\hline $\mathrm{Cu}$ & $(\mathrm{mg} / \mathrm{I})$ & $<$ d.l. & $<$ d.I. & n.m. & $<$ d.I. & $<$ d.I. & $<$ d.I. & $<$ d.I. \\
\hline Fe & $(\mathrm{mg} / \mathrm{I})$ & 3100 & 2200 & n.m. & 14300 & 14500 & 35900 & 110 \\
\hline $\mathbf{K}$ & $(\mathrm{mg} / \mathrm{I})$ & 2 & 4 & n.m. & 5 & 7 & 8 & 14 \\
\hline $\mathbf{P}$ & $(\mathrm{mg} / \mathrm{I})$ & 84 & 49 & n.m. & 407 & 263 & 575 & 3 \\
\hline $\mathbf{s}$ & $(\mathrm{mg} / \mathrm{I})$ & 6 & 14 & n.m. & 32 & 63 & 84 & 2047 \\
\hline As & $(\mu g / I)$ & 7 & 603 & n.m. & 34 & 3685 & 9626 & 115 \\
\hline Cd & $(\mu \mathrm{g} / \mathrm{I})$ & $<$ d.l. & $<$ d.I. & n.m. & $<\mathrm{d} . \mathrm{l}$. & $<$ d.I. & $<$ d.l. & $<$ d.l. \\
\hline $\mathbf{C r}$ & $(\mu \mathrm{g} / \mathrm{I})$ & 62 & 148 & n.m. & 322 & 980 & 1474 & 1734 \\
\hline $\mathbf{N i}$ & $(\mu \mathrm{g} / \mathrm{I})$ & $<$ d.l. & 16 & n.m. & 88 & 286 & 478 & 908 \\
\hline $\mathbf{P b}$ & $(\mu \mathrm{g} / \mathrm{I})$ & $<$ d.l. & <d.l. & n.m. & 4 & 33 & 36 & <d.l. \\
\hline Fe-DTPA & $(\mathrm{mg} / \mathrm{L})$ & n.m. & 91 & $\mathrm{n} . \mathrm{m}$ & $\mathrm{n} . \mathrm{m}$ & n.m & $\mathrm{n} . \mathrm{m}$ & n.m. \\
\hline
\end{tabular}

a Na uitzakken en afgieten van het supernatant.

b Niet geanalyseerd i.v.m. nalevering monster.

\subsubsection{Effect van HumVi dosering op de ijzerconcentraties in het supernatant}

Er wordt verwacht dat de beschikbaarheid van ijzer voor plantopname hoger is voor ijzerdeeltjes die goed oplosbaar of stabiel zijn in water, omdat deze ijzerdeeltjes door het bodemvocht heen getransporteerd kunnen worden naar de wortel. Dit in tegenstelling tot grote ijzerhydroxide deeltjes, die alleen als ijzernutriënt kunnen dienen nadat deze zijn opgelost. Door centrifugescheiding kunnen de grotere colloïden gescheiden worden van het opgeloste ijzer en de zeer kleine en stabiele colloïden. Daarom is in het volgende experiment het effect bepaald van een HumVi-dosering op de ijzerconcentraties in het supernatant na centrifugeren bij 3500 rpm.

Figuur 3.6 toont de ijzerconcentratie in het supernatant van ijzerspoelwater of ijzerslib na toevoegen van 2,5 tot $25 \%$ HumVi. De ijzerconcentratie is bepaald in de vloeistof nadat grotere deeltjes door middel van centrifugeren zijn verwijderd. Er is geen filtratie toegepast.

Zonder HumVi-dosering bevat het supernatant nagenoeg geen ijzer (Tabel 3.7, $\mathrm{Fe}<0,3 \mathrm{mg} / \mathrm{I}$ ). $\mathrm{Na}$ additie van HumVi wordt een zeer sterke toename in de ijzerconcentratie in het supernatant waargenomen tot concentraties in de orde van grammen per liter. Tot een HumVi-dosering van $10 \%$ 
neemt de ijzerconcentratie in het supernatant toe bij een toenemende HumVi-dosering.

IJzerconcentraties in het supernatant zijn aanzienlijk hoger na additie van HumVi aan ijzerslib in vergelijking met ijzerspoelwater. De hoogste ijzerconcentratie $(13 \mathrm{~g} \mathrm{Fe} / \mathrm{L}$ ) wordt behaald na dosering van HumVi aan ijzerslib van locatie Hammerflier. Figuur 3.5 toont de ijzerconcentratie in het supernatant als percentage van het totale ijzergehalte in het uitgangsmateriaal. Hieruit blijkt dat het percentage van het totale ijzer dat na HumVi-additie naar het supernatant gaat, vergelijkbaar is voor ijzerspoelwater en ijzerslib. Dit toont aan dat de hogere ijzerconcentraties in het supernatant van ijzerslib met HumVi samenhangt met het hogere totale ijzergehalte in ijzerslib.

Tevens is getest of de ijzerconcentratie in het supernatant toeneemt wanneer de schudtijd wordt verlengd tot 24 of 96 uur. Uit deze test, uitgevoerd met een HumVi-dosering van $25 \%$, blijkt dat de ijzerconcentratie niet toeneemt bij een langere schudtijd (resultaten niet opgenomen). Wel is er sprake van een relatief grote spreiding in ijzerconcentraties in de diverse monsters, wat waarschijnlijk verklaard kan worden door het feit dat ijzerslib zich lastig laat bemonsteren waardoor het totale ijzergehalte in de verschillende submonsters mogelijk varieert.
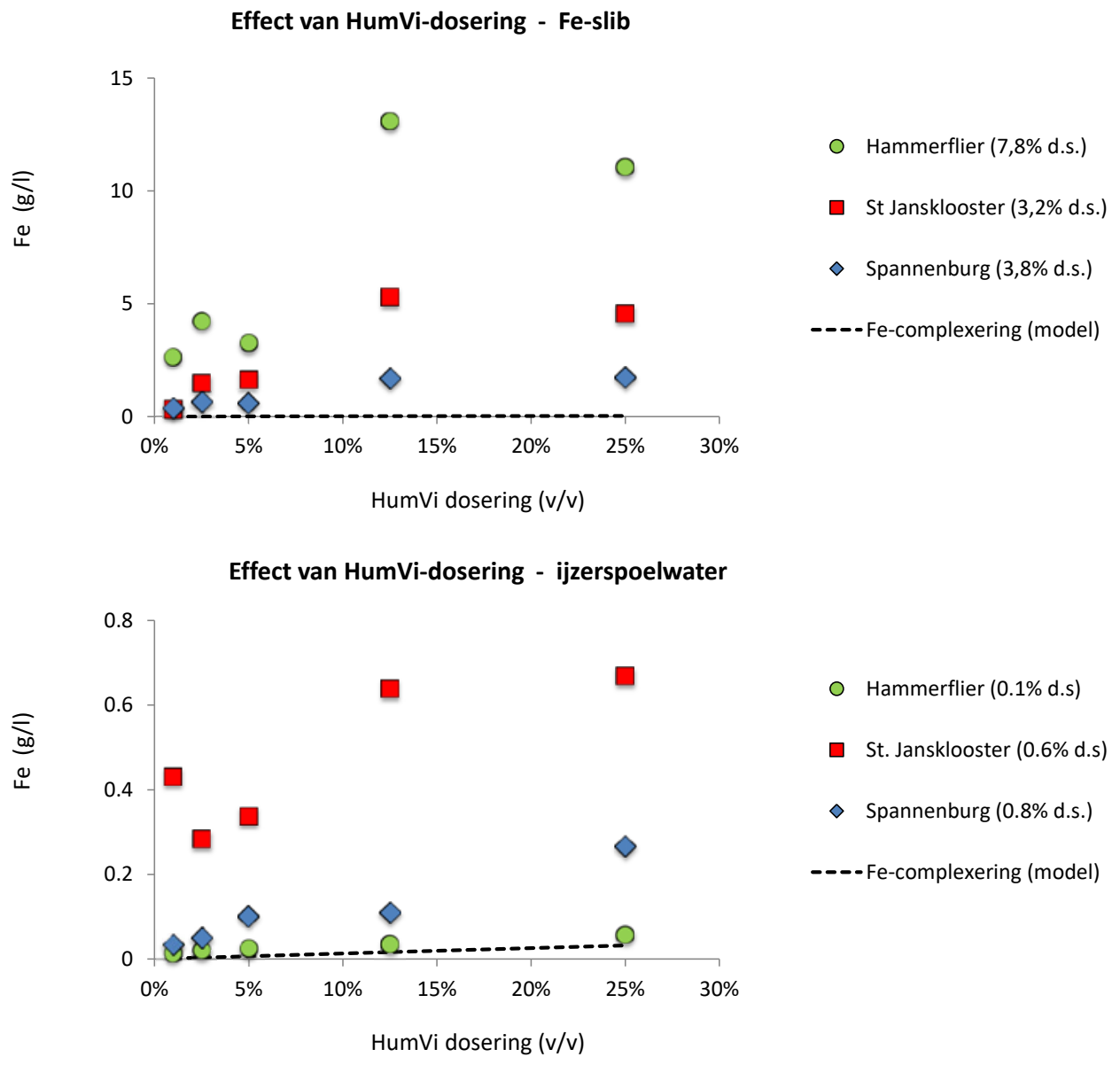

Figuur 3.4 IJzerconcentraties (totaal $\mathrm{Fe}$ ) in het supernatant als functie van de HumVi-dosering voor ijzerslib (boven) en ijzerspoelwater (onder) van drie drinkwaterwinningslocaties. Tussen haakjes is het drogestofgehalte van het ijzerwater weergegeven. De stippellijn toont de berekende ijzercomplexatie aan fulvozuur (zie paragraaf 3.2.3). 

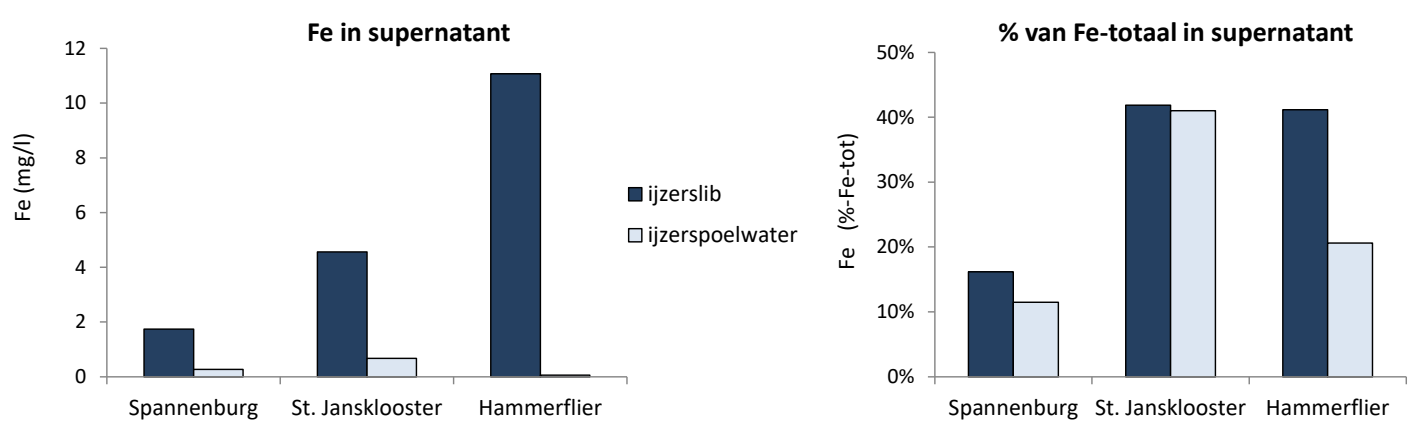

Figuur 3.5 IJzerconcentratie in het supernatant van ijzerspoelwater (links) en als percentage van Fe-totaal in het uitgangsmateriaal (rechts) bij een HumVi-dosering van $25 \%$.

\subsubsection{IJzerspeciatie in het supernatant}

De sterke toename in ijzerconcentraties in het supernatant van ijzerslib na additie van HumVi kan duiden op twee processen:

- Complexering van $\mathrm{Fe}^{3+}$ aan fulvozuur;

- Dispergeren van ijzerhydroxide colloïden welke gestabiliseerd worden door fulvozuur.

Het is niet mogelijk om beide ijzervormen op basis van een standaard analytische methode te onderscheiden. Om een beeld te krijgen van de bijdrage van de deeltjesgrootte van de ijzervormen is de ijzerconcentratie in het supernatant vergeleken met de ijzerconcentratie na filtratie over $0,45 \mu \mathrm{m}$ (Figuur 3.6). Omdat de filtratie van het supernatant moeilijk verloopt door het dichtslibben van de filters, is het supernatant voor filtratie 50 of $500 x$ verdund. Uit de metingen blijkt dat er bij een sterkere verdunning een hoger aandeel ijzer het filter passeert en dus in de $<0,45 \mu \mathrm{m}$ fractie valt. Bij een sterkere verdunning slibt het filter minder snel dicht, waardoor meer colloïden het filter passeren. Dit wijst dus op de aanwezigheid van colloïden. De TOC-concentratie in het gefiltreerde supernatant is nagenoeg gelijk aan de TOC-concentratie in het niet-gefiltreerde monster (resultaten niet opgenomen). Dit wijst erop dat ijzer niet gecomplexeerd is aan fulvozuur, maar grotendeels aanwezig is in de vorm van colloïden en nanodeeltjes. Nanodeeltjes zijn gedefinieerd als deeltjes tussen 1 en enkele honderden nanometers, en colloïden als deeltjes tussen 100 en 1000 nanometer. Dit wordt verder ondersteund door de observatie dat de Fe-concentratie niet evenredig toeneemt met de HumVi-dosering (Figuur 3.4) en dat er grote verschillen zijn tussen de diverse locaties. Zodoende wordt geconcludeerd dat het ijzer in het supernatant grotendeels aanwezig is in de vorm van ijzerhydroxide nanodeeltjes.

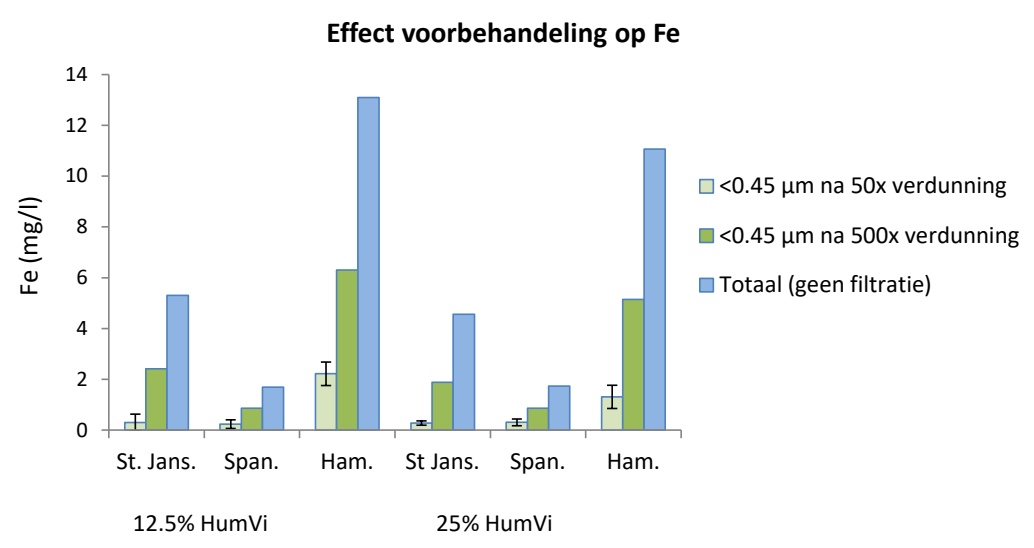

Figuur 3.6 IJzerconcentratie in het supernatant van ijzerslib met 12,5 of 25\% HumVi, gemeten na (i) 50x verdunning gevolgd door filtratie over 0,45 $\mu \mathrm{m}$ filtratie, (ii) 500x verdunning gevolgd door filtratie over 0,45 $\mu \mathrm{m}$ en (iii) de totale ijzerconcentratie gemeten op niet-gefiltreerde monsters. 
De verdeling van het ijzer in het supernatant van ijzerslib en ijzerwater na HumVi-additie over de fractie kleiner en groter dan 0,45 $\mu \mathrm{m}$ is weergegeven in Figuur 3.7. Grofweg de helft van het ijzer in Fe-HumVi is aanwezig in de vorm van Fe-oxide nanodeeltjes $(<450 \mathrm{~nm})$ en de andere helft is aanwezig in de vorm van Fe-oxide colloïden $(>450 \mathrm{~nm}$ ). De verdeling van ijzer over grotere en kleinere colloïden is dus vergelijkbaar voor producten gemaakt op basis van ijzerspoelwater of van ijzerslib.

\section{Fe-speciatie in Fe-HumVi producten}

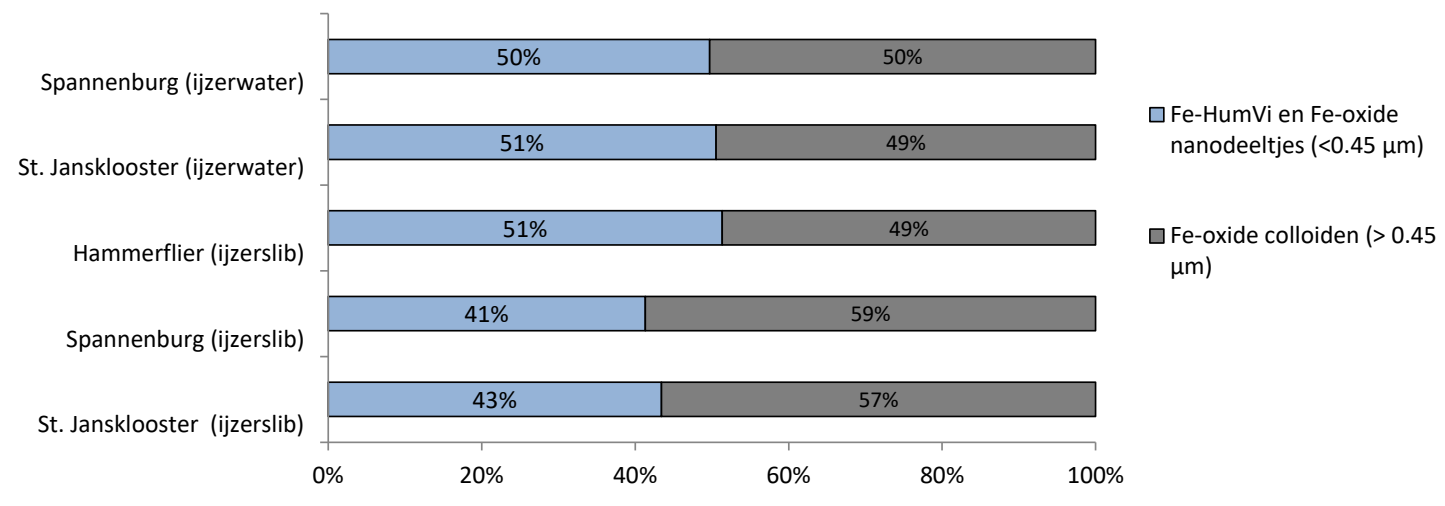

Figuur 3.7 Verdeling van ijzer in het Fe-HumVi-product (supernatant) over de fractie kleiner en groter dan 0,45 $\mu \mathrm{m}$ in een monster na verdunning (500x).

De bovenstaande resultaten wijzen erop dat ijzer in het supernatant grotendeels aanwezig is in de vorm van colloïden en niet of in mindere mate in de vorm van Fe-fulvozuur-complexen. De bijdrage van ijzercomplexering aan fulvozuur kan ook geschat worden op basis van berekeningen op basis van de fulvozuur concentratie, de $\mathrm{pH}$ en de adsorptie-constanten van ijzer en competiterende ionen ( $\mathrm{Na}$, Ca etc.) (). De uitkomsten van deze berekening is toegevoegd aan Figuur 3.4. Hieruit volgt dat minder dan $1 \%$ van het ijzer in het supernatant aanwezig is als $\mathrm{Fe}^{3+}$ dat is gecomplexeerd met fulvozuren.

De modelmatig berekende Fe/TOC-verhouding voor adsorptie van ijzer aan fulvozuur (onder relevante condities) bedraagt $1 \mathrm{~g} \mathrm{Fe} / \mathrm{kg}$ TOC. Dit getal kan vergeleken worden met gemeten ijzerbinding aan fulvozuur in de literatuur (paragraaf 3.2.4). Pinton et al. (1999) hebben humuszuren (waterextractable humic substances, WEHS) opgeladen met ijzerchloride via een kationen-omwisselingsproces. Humuszuren zijn aangezuurd tot $\mathrm{pH} 2$ en verzadigd met natrium alvorens deze over een kolom te leiden waar omwisseling van $\mathrm{Na}^{+}$voor $\mathrm{Fe}^{3+}$ plaatsvindt. Op deze wijze wordt een product verkregen waarbij Fe uitsluitend gebonden is aan humuszuur in de vorm van $\mathrm{Fe}^{3+}$. Het uiteindelijke product bevatte $2,2 \mathrm{~g} \mathrm{Fe} / \mathrm{kg}$ TOC. Deze experimenteel bepaalde waarde is vergelijkbaar met de berekende Fe/TOC-ratio ( $1 \mathrm{~g} \mathrm{Fe} / \mathrm{kg} \mathrm{TOC}$ ). Zowel de modelmatige aanpak als de analytische bepaling wijst er dus op dat humuszuren onder relevante condities grofweg 1 tot 2 gram Fe ${ }^{3+}$ per $\mathrm{kg} \mathrm{TOC}$ kunnen binden.

De Fe/TOC-ratio's in de Fe-HumVi-producten zijn echter 100 tot 1000 maal hoger dan de Fe/TOCratio's uit het werk van Pinton en de modelberekening. Deze hoge Fe/TOC-ratio's kunnen onmogelijk verklaard worden door $\mathrm{Fe}^{3+}$ complexering met fulvozuur. Hieruit kan worden geconcludeerd dat FeHumVi hoofdzakelijk bestaat uit Fe in colloïdale vorm en dus in essentie verschillend is van het WEHSFe-product van Pinton et al. (1999).

Het is niet mogelijk om met ijzerslib of ijzerspoelwater een Fe-HumVi-product te maken op basis van $\mathrm{Fe}^{3+}$ geadsorbeerd aan fulvozuur. In theorie is het mogelijk om HumVi op te laden met ijzerchloride zout door gebruik te maken van een ionenwisselaar zoals beschreven door Pinton et al. Echter, in dit geval zal de ijzerconcentratie in een oplossing met $100 \%$ HumVi (circa $100 \mathrm{~g} \mathrm{TOC}$ ) niet hoger worden dan $0,3 \mathrm{~g} / \mathrm{l}$, waardoor de marktwaarde van het product zeer beperkt zal zijn. Er wordt daarom gestreefd naar een product met een aanzienlijk hogere ijzerconcentratie. 
Tabel 3.11 Berekende en gemeten ratio's tussen ijzer en TOC in diverse producten en op basis van literatuur.

\begin{tabular}{llll} 
Vormingsmechanisme & $\mathrm{pH}$ & $\mathrm{Fe} / \mathrm{TOC}(\mathrm{g} / \mathrm{kg})$ & Referentie \\
IJzerslib $+25 \%$ HumVi & $6,7-8,3$ & $200-2000$ (totaal) & Deze studie \\
& & $100-1000(<0,45 \mu \mathrm{m})$ & \\
\hline WEHS $+\mathrm{FeCl}_{3}{ }^{1}$ & Onbekend & 2,2 & Pinton et al. 1999 \\
\hline Fulvozuur + ijzerslib & 7,5 & 1 & Modelberekening (deze studie) \\
\hline 1 & Omwisseling van natrium voor ijzer via kationenomwisseling. pH-waarde tijdens omwisseling onbekend.
\end{tabular}




\subsection{Stabiliteit van Fe-HumVi in de bodem}

\subsubsection{Test 1}

De mate waarin Fe-HumVi in oplossing blijft na toevoeging aan grond is getest met vier gronden (Tabel 3.12) en vier Fe-HumVi-producten. Figuur 3.8 toont de Fe-concentraties in de waterfase van de bodemsuspensies na dosering van Fe-HumVi, ijzerchelaat, HumVi of demiwater. Alle behandelingen met een ijzermeststof hebben dezelfde ijzerdosering ontvangen corresponderend met de stippellijn in Figuur 3.8. De Anatolia-grond uit Turkije kenmerkt zich door ijzergebrek en een zeer laag Fe-DTPAgehalte $(2,3 \mathrm{mg} / \mathrm{kg})$. Bij een Fe-DTPA-gehalte lager dan $5 \mathrm{mg} / \mathrm{kg}$ wordt de grond als ijzer-deficiënt beschouwd (Lindsay and Norvell, 1978).

Tabel 3.12 Eigenschappen van de gebruikte landbouwgronden. Anatolia-grond uit Turkije is een typische grond waarbij Fe-gebrek optreedt door de hoge $\mathrm{pH}$.

\begin{tabular}{|c|c|c|c|c|c|c|c|}
\hline $\mathrm{Nr}$ & Omschrijving & Herkomst & $\begin{array}{l}\mathrm{pH} \\
(-)\end{array}$ & $\begin{array}{l}\text { SOC } \\
(\%)\end{array}$ & $\begin{array}{l}\text { Klei } \\
(\%)\end{array}$ & $\begin{array}{l}\text { Kalk } \\
(\%)\end{array}$ & $\begin{array}{l}\text { Fe-DTPA } \\
(\mathrm{mg} / \mathrm{kg})\end{array}$ \\
\hline 1 & Anatolia-grond met ijzergebrek & Turkije & 7,5 & 1 & 22 & 9,3 & 2,3 \\
\hline 24 & Kalkhoudende grond & NL & 6,9 & 1,2 & 7 & 1,7 & n.m. \\
\hline 28 & Kalkrijke grond & NL & 7,2 & 0,6 & 3 & 2,7 & n.m. \\
\hline
\end{tabular}

De synthetische ijzermeststof Fe-HBED blijft in alle vier gronden nagenoeg volledig in oplossing gedurende een periode van 28 dagen. De Fe-DTPA-meststof is zeer stabiel in gronden met een lichtzure $\mathrm{pH}$ (grond 24 en 19), maar vertoont meer dan 50\% afname in gronden met een $\mathrm{pH}$ hoger dan 7 (grond 1 en 28). Deze resultaten komen overeen met de verwachtingen. Fe-HBED is speciaal ontwikkeld voor toepassing in alkaline gronden en kenmerkt zich door een zeer hoge bindingscoëfficiënt voor ijzer. Daarentegen zal Fe-DTPA vanwege de lagere bindingscoëfficiënt eerder ijzer loslaten en is dit zodoende vooral geschikt voor toepassing bij neutrale/lage zuurgraad van de bodem.

De stabiliteit van de Fe-HumVi-producten toont grote verschillen tussen de geteste gronden. De hoogste ijzerconcentraties worden gevonden in de kalkhoudende grond (24). Hier blijft Fe-HumVi gedurende de eerste twee weken in zeer hoge mate in oplossing (>60\%), maar na 4 weken toont de Fe concentratie een duidelijke afname. Voor grond 19 zien we ook redelijk hoge Fe-concentraties en, opvallend, een toename van de Fe-concentratie in de tijd. Mogelijk is HumVi in staat om uit deze grond Fe uit de bodem op te nemen en in oplossing te brengen. In grond 1 (grond met een lage ijzerbeschikbaarheid) en grond 28 (kalkrijke grond) neemt de Fe-concentratie na Fe-HumVi-dosering in de tijd af tot waarden vergelijkbaar met de blanco zonder Fe-nutriënt. In tegenstelling tot de synthetische Fe-chelaten, is de zuurgraad van de bodem dus geen verklarende factor voor de ijzerconcentratie. Ook zijn er correlaties gevonden tussen de ijzerconcentratie na Fe-HumVi-additie en andere bodemeigenschappen (organische stof, klei, kalk). Het is dus vooralsnog onduidelijk waarom additie van Fe-HumVi niet in alle gronden leidt tot langdurige verhoging van de ijzerconcentratie in het vocht.

Wanneer we de stabiliteit van de vier verschillende Fe-HumVi-producten bekijken, blijkt dat het product op basis van slib van Spannenburg de hoogste stabiliteit kent. Na 28 dagen is nog ruim 50\% van dit product in oplossing. Hammerflier geeft gemiddeld gezien de laagste Fe-concentraties ongeacht het HumVi-gehalte van het product. Deze verschillen zijn waarschijnlijk gerelateerd aan de verschillen in Fe/TOC-ratio waarbij een groter deel van het ijzer in oplossing blijft bij een lagere $\mathrm{Fe} / \mathrm{TOC}$-ratio. 

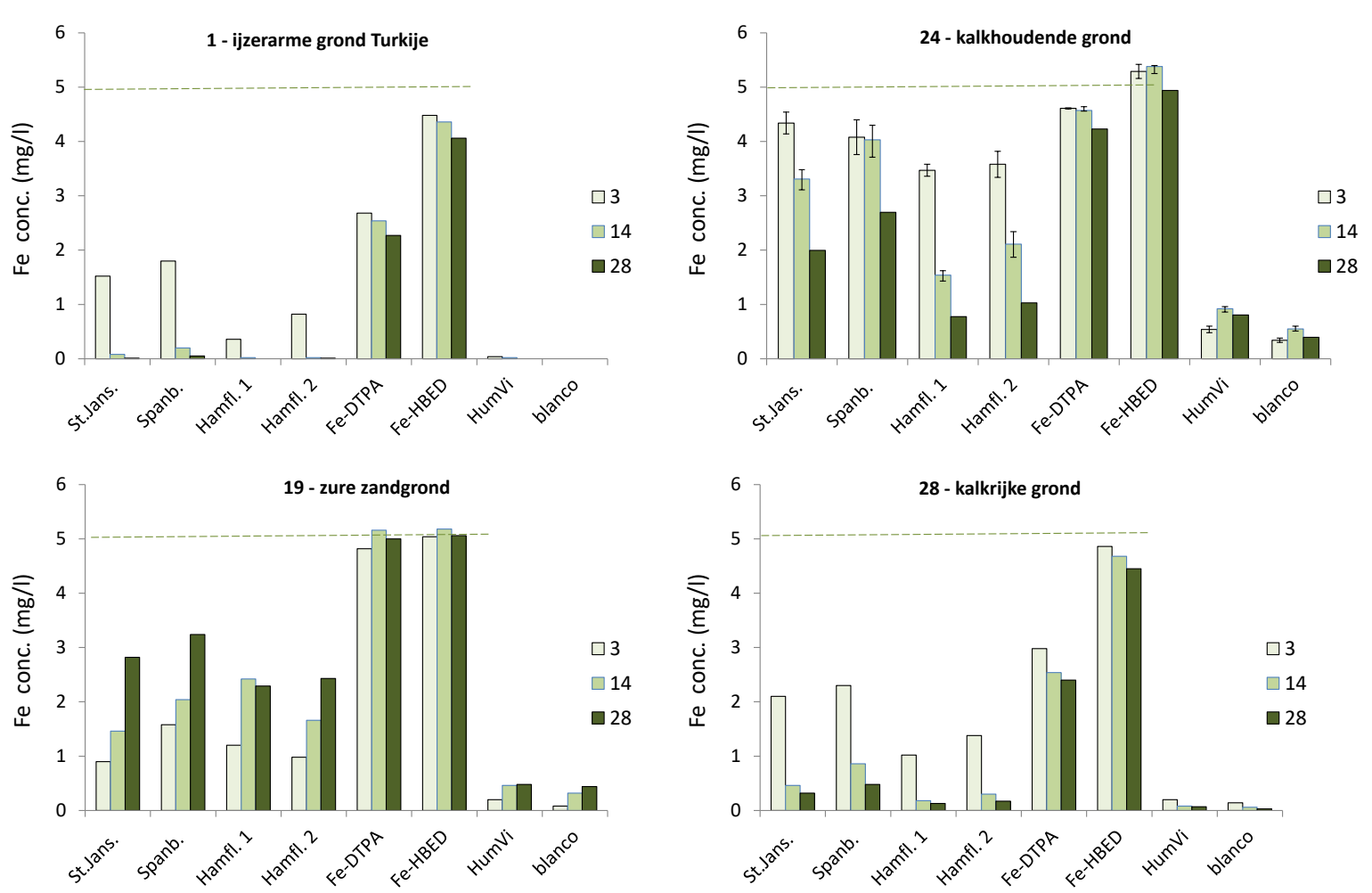

Figuur 3.8 IJzerconcentratie in het bodemvocht van 4 gronden en na 3, 14 en 28 dagen na additie van Fe-HumVi, twee Fe-chelaatmeststoffen, HumVi en demiwater (blanco). Stippellijn = dosering. FeHumVi-producten: St. Jansklooster+25\% HumVi, Spannenburg $+25 \%$ HumVi, Hammerflier $+12 \%$ HumVi (Hamfl 1), Hammerflier + 25\% HumVi (Hamfl. 2).

\section{DO- concentraties na Fe-HumVi-additie}

Met additie van Fe-HumVi-producten wordt naast ijzer een aanzienlijke hoeveelheid DOC in de vorm van fulvozuren gedoseerd. Figuur 3.9 toont de DOC-concentratie in de waterfase van de bodemsuspensies 28 dagen na dosering van Fe-HumVi. De DOC-concentratie is sterk verhoogd ten opzichte van de controlebehandeling waar alleen demiwater is gedoseerd. Figuur 3.10 toont de DOCconcentraties (na correctie voor de meting in de controle) als percentage van het gedoseerde DOC. Hieruit blijkt dat 55 tot $85 \%$ van het gedoseerde fulvozuur na 28 dagen nog in oplossing aanwezig is. Er vindt dus maar weinig adsorptie van fulvozuur aan de bodem plaats. HumVi is dus in staat om de DOC-concentratie in het bodemvocht gedurende lange tijd sterk te verhogen. Er is geen correlatie gevonden tussen de DOC- en ijzerconcentraties in de waterfase van de bodemsuspensies. Dit betekent dat een lage stabiliteit van het Fe-HumVi niet gerelateerd is aan een verlies van fulvozuren door binding aan de bodem.

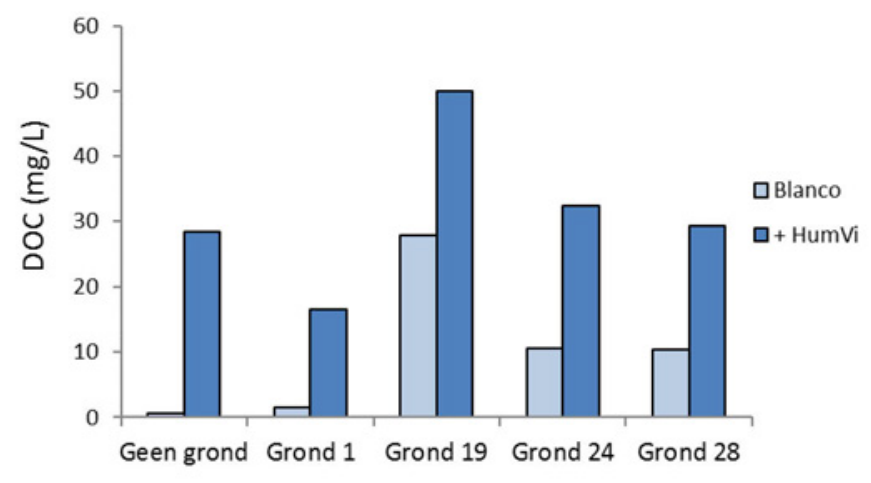

Figuur 3.9 DOC-concentraties in de waterfase van de bodemsuspensie bij de referentiebehandeling (demiwater) en na additie van Fe-HumVi voor vier gronden. Metingen 28 dagen na additie van FeHumVi (ijzerslib locatie Spannenburg). 


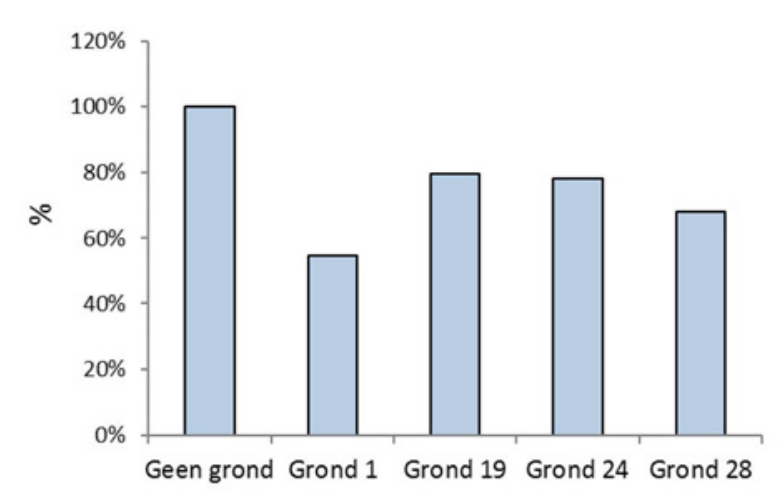

Figuur 3.10 DOC-concentratie in de waterfase van de bodemsuspensie na Fe-HumVi-dosering, gecorrigeerd voor de DOC-concentratie in referentie en uitgedrukt als percentage van het gedoseerde HumVi. Metingen 28 dagen na additie van Fe-HumVi aan grond (ijzerslib locatie Spannenburg).

\section{Effect van Fe-HumVi op fosfaatconcentraties}

De P-totaalconcentratie in het bodemvocht na additie van Fe-HumVi is weergegeven in Figuur 3.10 voor grond 24 . Voor de andere gronden wordt een vergelijkbaar beeld waargenomen. De fosfaatconcentratie in de controlebehandeling verschilt niet van de fosfaatconcentratie na dosering van HumVi. Met andere woorden, HumVi heeft bij de geteste dosering geen effect op de fosfaatconcentratie. Ook bij de Fe-HumVi worden vergelijkbare fosfaatconcentraties gevonden. Bij de eerste twee Fe-HumVi-producten, met de hoogste DOC-gehalten, is een lichte verhoging in fosfaatconcentratie zichtbaar. De verschillen zijn echter niet statistisch significant. Er kan dus gesteld worden dat de additie van Fe-HumVi geen significant effect heeft op de beschikbaarheid van fosfaat.

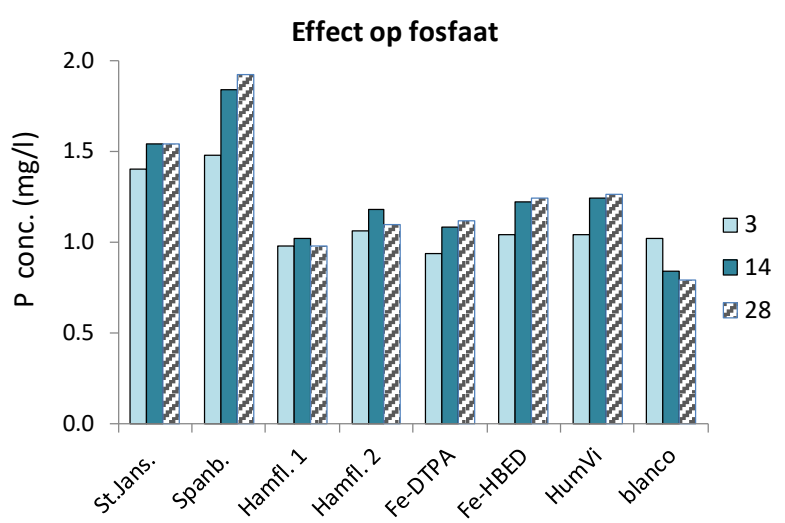

Figuur 3.11 Concentratie P-totaal in de waterfase van bodemsuspensies na dosering van Fe-HumVi en ijzerchelaten voor grond 24.

\section{Effect van Fe-HumVi op koper- en zinkconcentraties}

Synthetische chelaten hebben, naast een hoge affiniteit voor ijzer, ook een hoge affiniteit voor koper en zink. Koper en zink zijn micronutriënten, maar hoge concentraties in het bodemvocht kunnen leiden tot toxiciteit of uitspoeling. Figuur 3.11 toont dat de zinkconcentratie in de bodemoplossing zeer sterk toeneemt na dosering van Fe-DTPA. De koperconcentratie in de bodem neemt zeer sterk toe na dosering van Fe-DTPA en Fe-HBED. Voor de Fe-HumVi-producten wordt in geen van de bodems een verandering in koper of zink aangetroffen. De metingen wijzen uit dat het gebruik van Fe-DTPA in bodems zal leiden tot een toename in koper- en zinkconcentraties in het bodemvocht, waardoor de uitspoeling en plantopname van deze elementen eveneens zal toenemen. De absolute toename in koper- en zinkconcentraties kan echter niet rechtstreeks naar het veld vertaald worden, omdat de laboratoriumtesten zijn uitgevoerd in een bodemsuspensie met een aanzienlijk hoger vochtgehalte dan in het veld verwacht kan worden. De absolute toename in koper- en zinkconcentraties bij gebruik van Fe-DTPA zullen daarom in een incubatieproef of potproef vastgesteld moeten worden. 

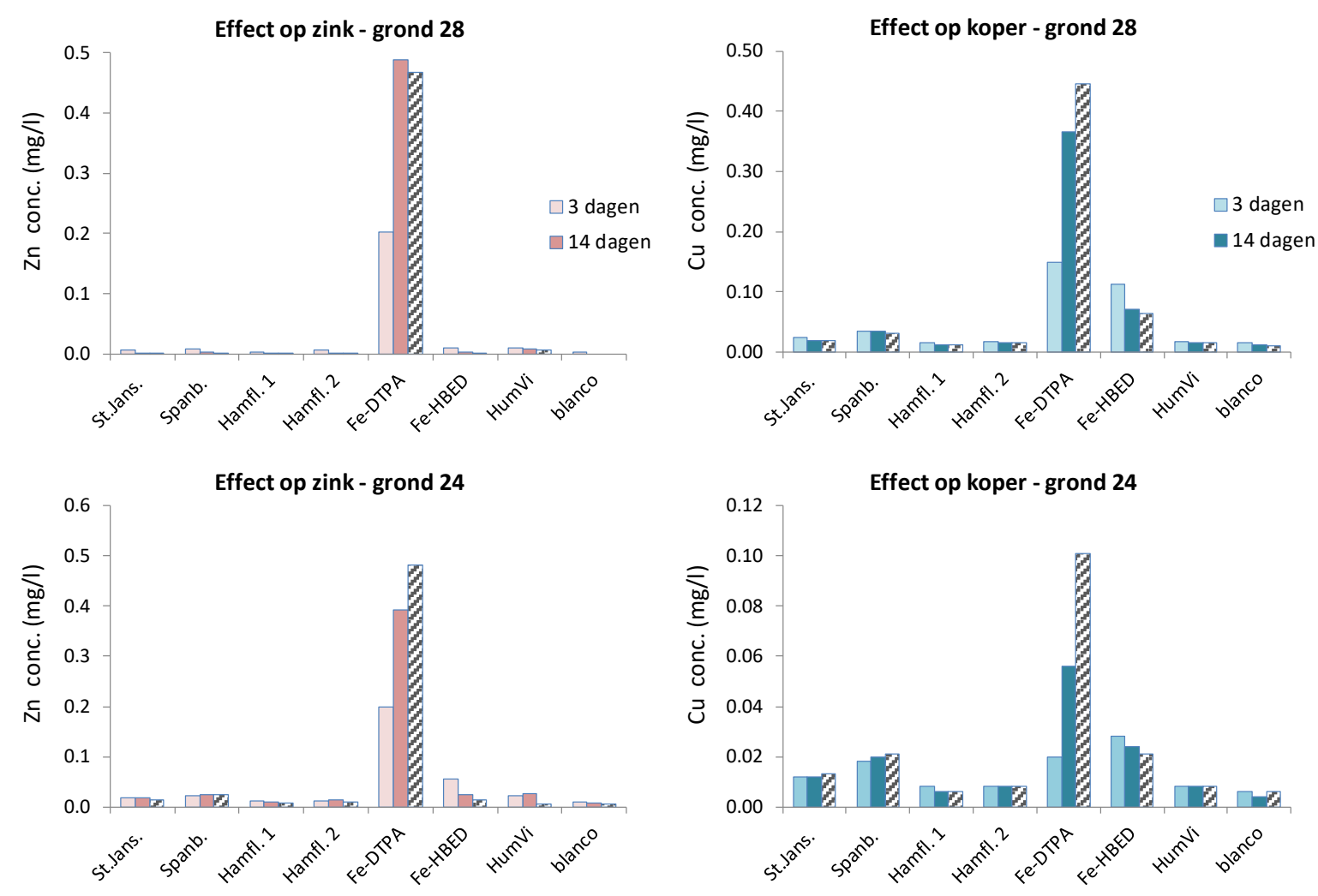

Figuur 3.12 Zink (links) en koper (rechts) concentraties in de waterfase van bodemsuspensies na additie van Fe-HumVi en commerciële ijzerproducten voor twee gronden.

\subsubsection{Test 2}

In de tweede test is één Fe-HumVi-product toegevoegd aan zes verschillende bodems met als doel een beter inzicht te krijgen in de bodemeigenschappen die de ijzerstabiliteit bepalen. Om de omstandigheden beter overeen te laten komen met de praktijk, is de proef ditmaal uitgevoerd bij een aanzienlijke hogere grond-vloeistofverhouding van $1: 2$ (40 g grond, $80 \mathrm{ml}$ vloeistof) waarbij een slurry ontstaat. Het vochtgehalte is hierbij nog altijd circa tienmaal hoger dan in veldvochtige grond.

De bodemeigenschappen van de zes Nederlandse landbouwgronden staat in Tabel 3.13. Grond van locatie Grebbedijk is voor deze proef relevant, omdat deze grond afkomstig is van de oeverwalgronden nabij Wageningen waar veel fruitteelt voorkomt. O.a. bij de teelt van perenbodem is bekend dat ijzerdeficiëntie kan voorkomen en ijzermeststoffen gebruikt worden. Ook Wijnandsrade en Epen zouden op basis van hun grondsoort en ligging geschikt kunnen zijn voor fruitteelt. Het Fe-DTPA-gehalte is een indicator voor de ijzerbeschikbaarheid. Bij een Fe-DTPA-gehalte lager dan $5 \mathrm{mg} / \mathrm{kg}$ wordt de grond als ijzer-deficiënt beschouwd (Lindsay and Norvell, 1978). Dit is bij geen van deze gronden het geval.

Tabel 3.13 Samenstelling zes gronden gebruikt in incubatieproef met Fe-HumVi.

\begin{tabular}{|c|c|c|c|c|c|c|}
\hline & Droevendaal & Cranendonck & Wijnandsrade & Epen & Grebbedijk & Lottum \\
\hline Grondsoort & Zand & Zand & Löss & Löss & Klei & Klei \\
\hline $\mathrm{pH}(-)$ & 6,08 & 5,32 & 6,57 & 6,1 & 7,38 & 6,36 \\
\hline Kalk (\%) & $<0,2$ & $<\mathrm{dl}$ & 0,2 & 0,4 & 1,8 & 0,6 \\
\hline Klei (\%) & 1 & 1 & 12 & 9 & 32 & 16 \\
\hline Fe-DTPA (mg/kg) & 102 & 118 & 33 & 61 & 45 & 30 \\
\hline
\end{tabular}


Figuur 3.13 toont de ijzerconcentraties in de waterfase van de bodem 14 dagen na additie van $0,0,8$ en $1,6 \mathrm{ml}$ Fe-HumVi product. Het verschil tussen de gemeten ijzerconcentratie en de verwachte ijzerconcentratie (lijn) geeft de hoeveelheid ijzer die uit de waterfase is verdwenen door coagulatie of binding aan de grond.

Wederom zijn de verschillen in ijzerstabiliteit van Fe-HumVi tussen de gronden zeer groot. In grond van de Grebbedijk (oeverwal), waar de ijzerconcentratie in de controlebehandeling zeer laag is, heeft additie van Fe-HumVi nauwelijks effect op de ijzerconcentratie in de waterfase. Na 14 dagen is nog 2 tot $4 \%$ van het gedoseerde Fe in oplossing. Ook voor de grond uit Epen geldt dat het Fe-HumVi-product niet in oplossing blijft. Daarentegen wordt in grond van Cranendonck en Lottum een zeer sterke verhoging van de ijzerconcentratie gemeten. In deze gronden blijft 50 tot $80 \%$ van het gedoseerde ijzer gedurende 14 dagen in oplossing. In alle gronden, met uitzondering van Grebbenberg, leidt de dosering van FeHumVi tot een substantiële toename in de ijzerconcentratie in de waterfase.
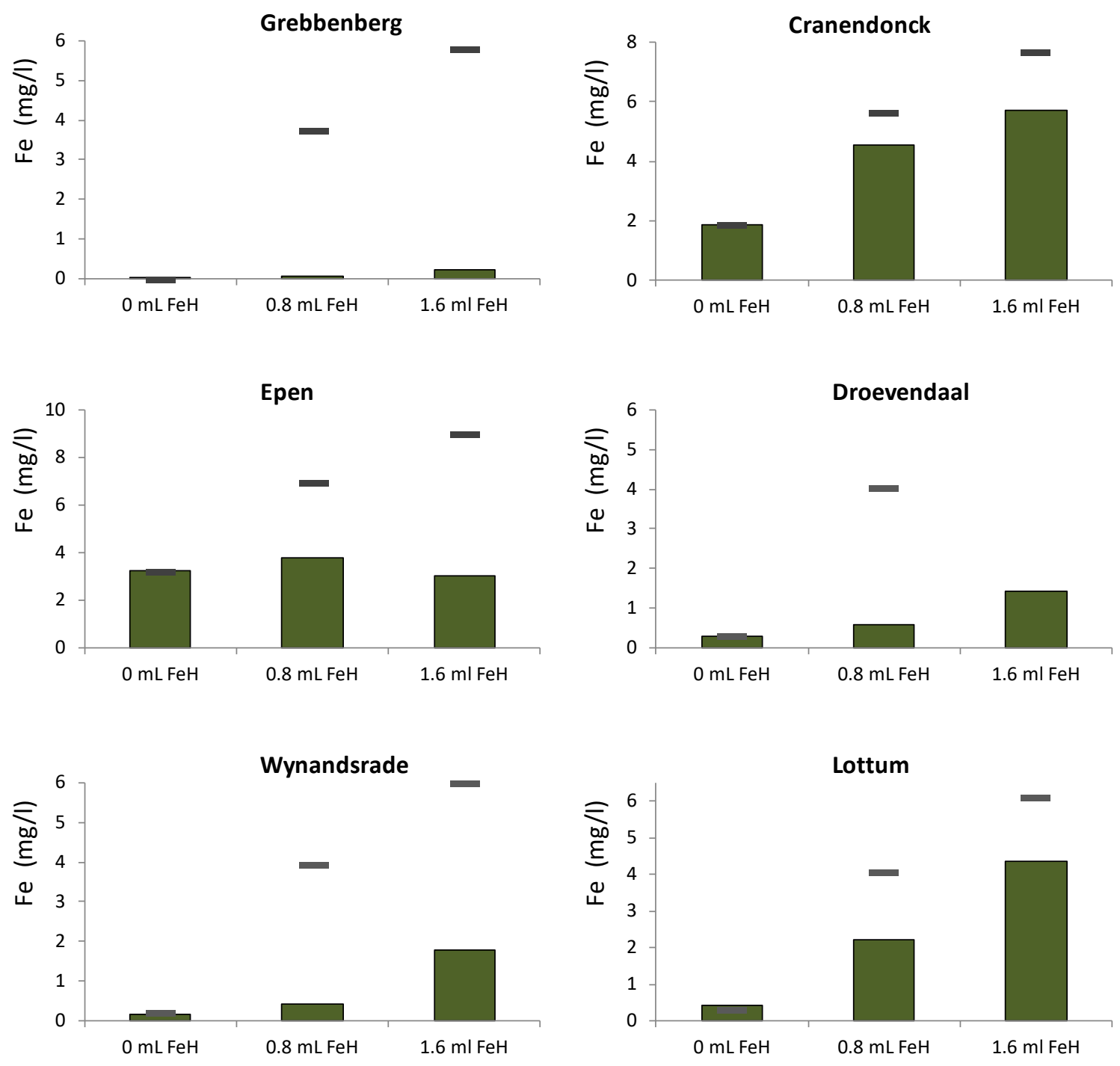

Figuur 3.13 IJzerconcentraties in de waterfase van de bodem 14 dagen na dosering van $0,0,8 \mathrm{ml}$ en 1,6 ml Fe-HumVi (FeH). De lijn geeft de ijzerconcentratie weer wanneer al het gedoseerde ijzer in oplossing zou blijven (dosering + Fe-concentratie in controle). 


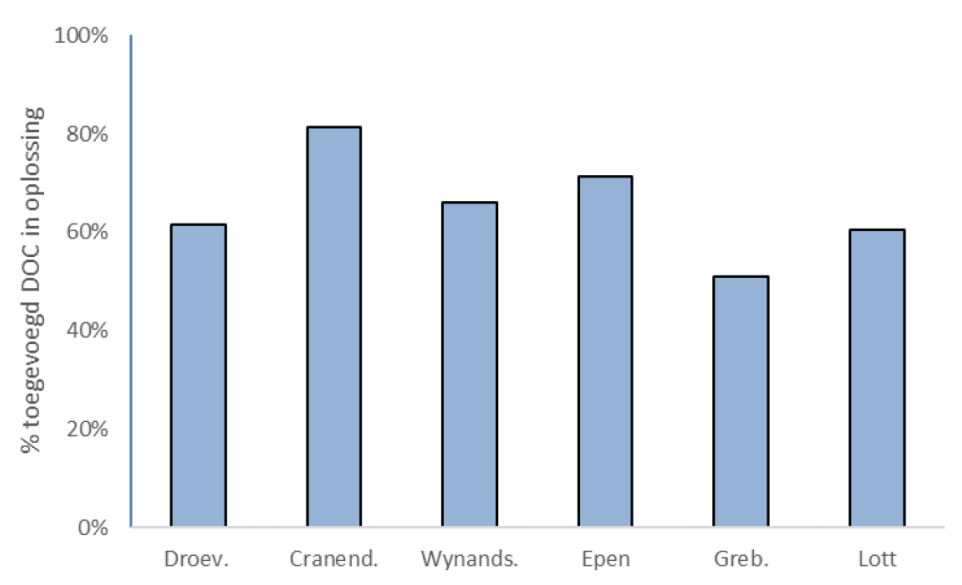

Figuur 3.14 Het percentage DOC, gedoseerd in de vorm van Fe-HumVi, dat 14 dagen na dosering aan de bodem nog in de bodemoplossing aanwezig is (bij dosering van 1,6 ml Fe-HumVi).

Gemiddeld is $60 \%$ van het gedoseerde fulvozuur (gedoseerd in de vorm van Fe-HumVi) na 14 dagen nog aanwezig in de waterfase van de bodem. Dit percentage is vrij constant tussen de zes gronden. Ook bij een tweemaal lagere dosering wordt een vergelijkbaar percentage van het gedoseerde DOC teruggevonden, evenals bij eerdere test met andere gronden (paragraaf 3.3.1). Hieruit blijkt dat de mate waarin het fulvozuur in oplossing blijft maar beperkt afhankelijk is van de bodemeigenschappen en grotendeels een eigenschap is van het HumVi product zelf. De DOC-concentraties in de waterfase van de grondmonsters na Fe-HumVi-additie bedragen 120-170 mg/L bij de lage dosering en tot 250$330 \mathrm{mg} / \mathrm{L}$ bij de hoge dosering. Er is geen correlatie tussen het percentage HumVi en het percentage Fe dat in oplossing blijft. Dit betekent dat het ijzer uit de oplossing verdwijnt, terwijl het fulvozuur grotendeels in de oplossing aanwezig blijft.

Om de grote variatie in stabiliteit (i.e. mate waarin Fe in oplossing blijft) van Fe-HumVi te kunnen verklaren, is gekeken naar correlaties tussen de ijzerconcentratie en een aantal bodemeigenschappen (Figuur 3.15). Hiervoor is het percentage ijzer dat na 14 dagen nog aanwezig is in de bodemoplossing (gecorrigeerd voor de controle) geplot tegen het organische-stofgehalte, kleigehalte, $\mathrm{pH}$ en de Caconcentratie in het bodemvocht. Hiervoor zijn de data van proef 1 en proef 2 gecombineerd. Een hoog calciumgehalte in het bodemvocht, en daarmee een hoog zoutgehalte, kan coagulatie van Fe-oxidedeeltjes veroorzaken. $\mathrm{Er}$ is een niet-lineaire relatie tussen Ca-concentratie en de stabiliteit van FeHumVi, maar deze wordt sterk bepaald door een aantal monsters met een zeer hoge Ca-concentratie. Op basis van de huidige kennis is het daarom niet mogelijk om de stabiliteit van Fe-HumVi in een bepaalde grond te voorspellen. 

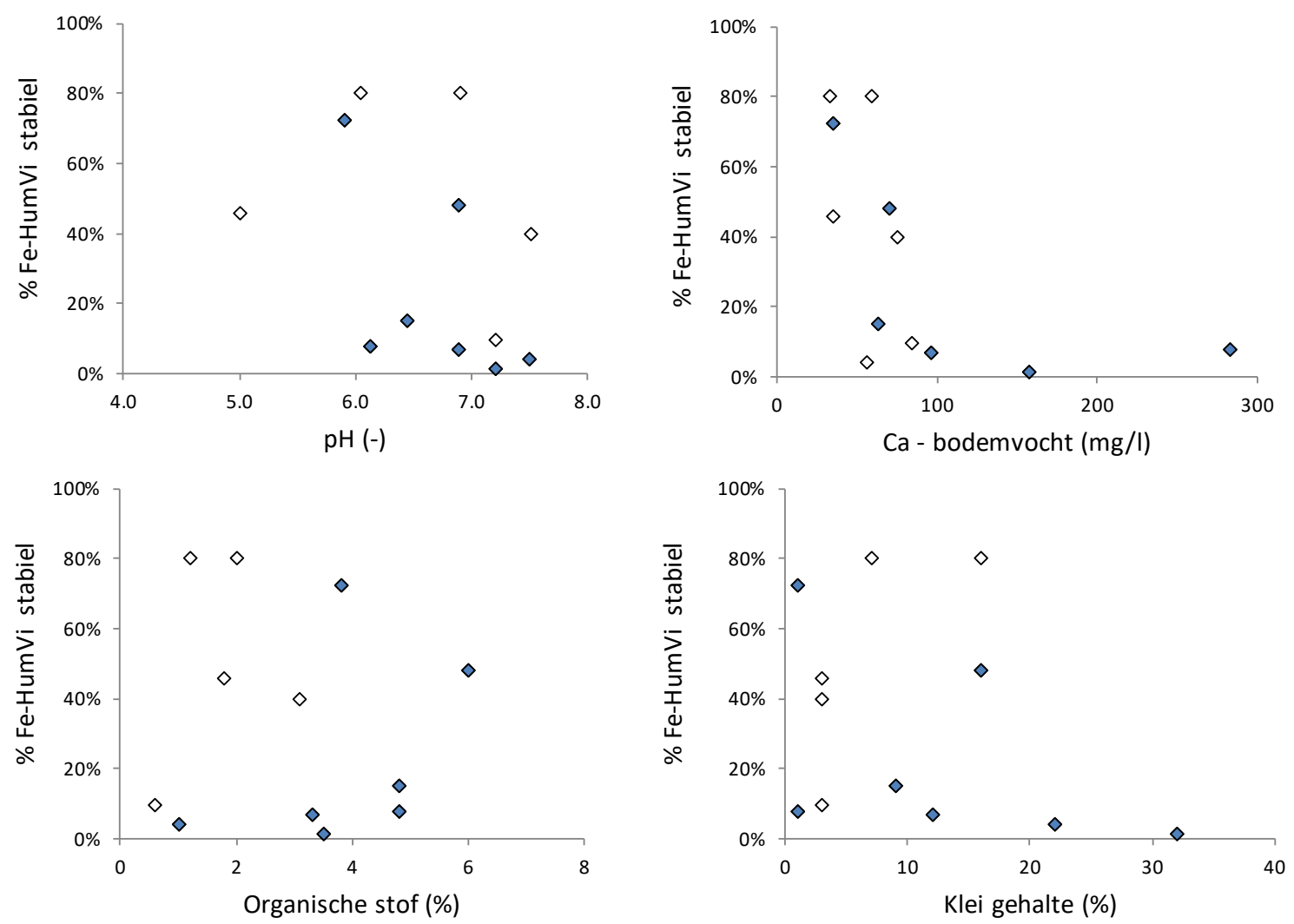

Figuur 3.15 Het percentage van het gedoseerde Fe-HumVi dat na 14 dagen nog aanwezig is in de bodemoplossing (\%Fe-HumVi Stabiel) geplot tegen de $\mathrm{pH}$, Fe-gehalte en organische-stofgehalte en het kleigehalte (blauwe symbolen: data test 1 met grond/water ratio van 1:10, witte symbolen: data test 2 met grond/water ratio van 1:2).

\section{Effect van Fe-HumVi-dosering op de fosfaatbeschikbaarheid}

Figuur 3.16 toont het effect van Fe-HumVi-dosering op de fosfaatconcentratie in het bodemvocht. Resultaten voor de Lottum grond zijn niet opgenomen omdat fosfaat hier bij alle behandelingen onder de detectielimit lag (fosfaatfixerende grond). Er wordt een lichte toename in de fosfaat concentratie bij een toenemende HumVi dosering geconstateerd. Deze proef is uitgevoerd met bodemslurries. Verder onderzoek moet uitwijzen of dit effect ook optreedt bij veldvochtige gronden. 

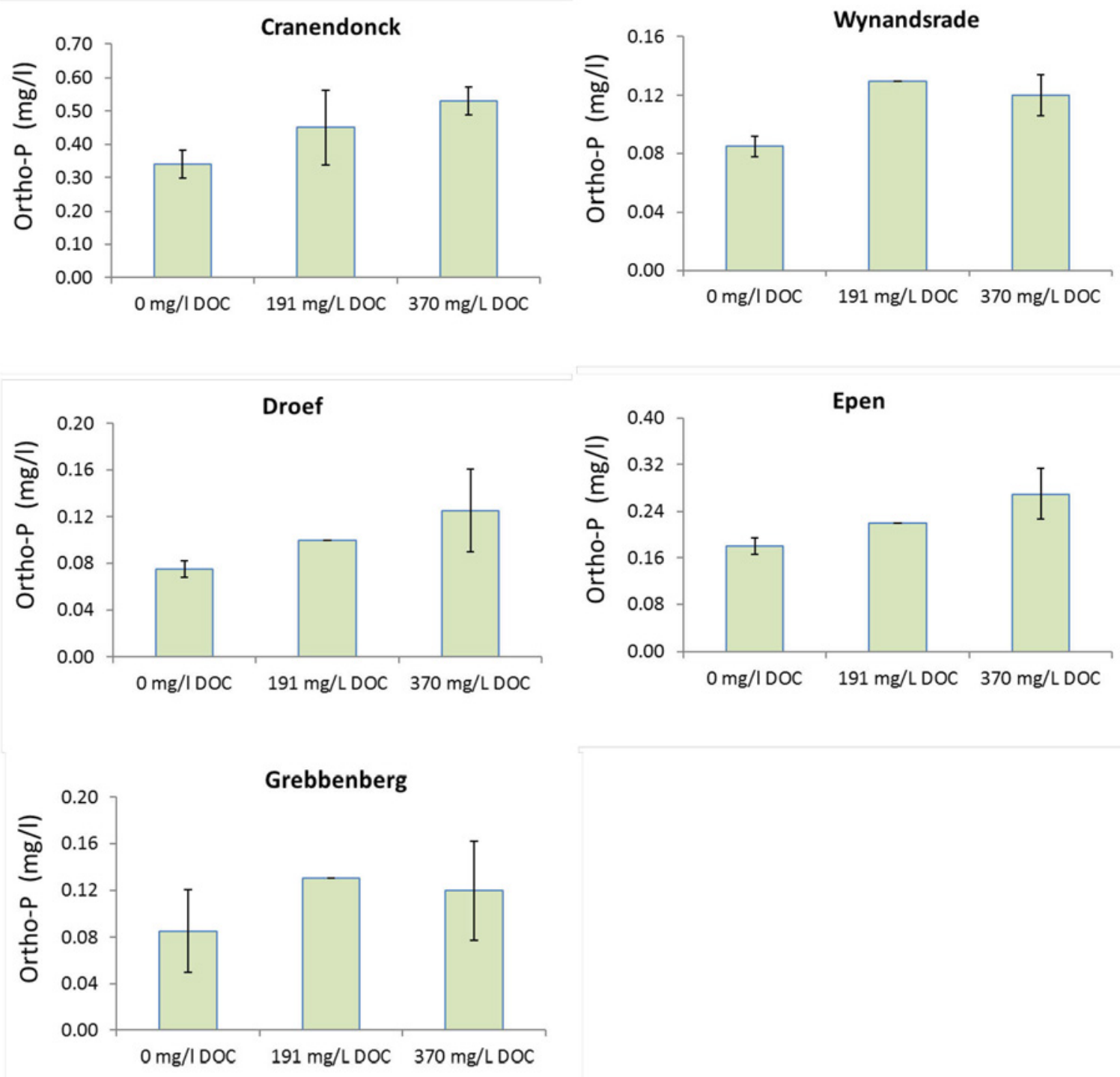

Figuur 3.16 Effect van Fe-HumVi-dosering (hier uitgedrukt in gedoseerde hoeveelheid TOC in mg per $L$ bodemvocht) op de ortho-P concentratie in het bodemvocht na 14 dagen. Gemiddelde en standaarddeviatie van twee herhalingen. Ortho-P-concentraties zijn gecorrigeerd voor de (zeer lage) ortho-P-dosering via het Fe-HumVi-product. 


\section{$4 \quad$ Synthese en conclusie}

Bij de productie van drinkwater uit grondwater worden grote hoeveelheden ijzerslib gevormd. Deze reststroom wordt nu veelal afgezet naar vergistingsinstallaties waar het gebruikt wordt om sulfide te binden. Daarnaast wordt bij de ontkleuring van water uit bronnen gelegen onder veenpakketten een fulvozuur-rijke reststroom (HumVi) geproduceerd. Dit product wordt reeds als biostimulant afgezet naar de land- en tuinbouw. Vitens wil de mogelijkheden onderzoeken om deze twee reststromen, na een eventuele opwerkingsstap, af te zetten als ijzermeststoffen voor toepassing in de land- en tuinbouw. Dit rapport beschrijft de resultaten van een serie laboratoriumexperimenten met ijzerslib en HumVi en vormt daarmee een eerste verkenning van de mogelijkheden om deze producten in te zetten als alternatief voor synthetische ijzerchelaatmeststoffen.

Om de potentie voor het gebruik van ijzerslib als ijzermeststof te kunnen beoordelen, was allereerst behoefte aan meer kennis over de samenstelling en fysisch-chemische eigenschappen van ijzerslib en de variatie daarin. De eerste fase van dit project bestond daarom uit een uitvoerige karakterisatie van ijzerspoelwater (niet ingedikt) en ijzerslib, wat verkregen wordt door het uitzakken van spoelwater na additie van poly-electroliet. Er zijn zes drinkwaterproductielocaties bemonsterd.

IJzerslib bevat grofweg 300-400 gram Fe/kg droge stof, wat betekent dat ijzerslib voor 50-75\% uit ijzerhydroxiden bestaat. Het kalkgehalte is sterk afhankelijk van de locatie en varieert van 1 tot $30 \%$ kalk. Daarnaast bevat ijzerslib circa 8 tot $14 \%$ organische stof. Deze organische stof is voor meer dan 95\% gebonden aan de vaste fase (i.e. de ijzerhydroxiden). Dit impliceert dat de ijzerhydroxiden een grote hoeveelheid organische stof kunnen binden en zodoende een groot specifiek oppervlak (i.e. $\left.\mathrm{m}^{2} / \mathrm{gram}\right)$ hebben. Op basis van de C/Fe ratio $(0,4-1,0 \mathrm{~mol} / \mathrm{mol})$ wordt geschat dat de deeltjes een specifiek oppervlak hebben van circa $200-400 \mathrm{~m}^{2} / \mathrm{gram}$ wat overeenkomt met een gemiddelde deeltjesgrootte van $10 \mathrm{~nm}$. Echter, analyse van de deeltjesgrootte met behulp van een Coulter-teller geeft aan dat de deeltjes circa 1-50 micrometer groot zijn. Dat geeft aan dat ijzerslib bestaat uit nanodeeltjes die samenklonteren tot aggregaten van enkele tientallen micrometers groot. IJzerslib bestaat uit grotere ijzerhydroxide-aggregaten in vergelijking met ijzerspoelwater, wat aangeeft dat de toevoeging van poly-electroliet leidt tot verdere aggregatie van deeltjes. De ijzerhydroxide deeltjes hebben een negatieve oppervlaktelading, wat eveneens ondersteunt dat deeltjes bedekt zijn met organische stof. Ook verklaart dit waarom het ontwateren van ijzerslib zonder poly-electroliet slecht verloopt. Bij bewaren is over een tijdsbestek van drie maanden geen verandering in de deeltjesgrootte waargenomen.

De werking van ijzerchelaatmeststoffen is gebaseerd op het feit dat deze meststoffen na toevoeging aan de bodem in oplossing blijven, waardoor het ijzer via het water naar de plantenwortel getransporteerd wordt. Zodoende kan verwacht worden dat de mogelijkheden om ijzerslib toe te passen als ijzermeststof afhangt van de mate waarin dit ijzer aanwezig is in de waterfase, waardoor het via het bodemvocht naar de wortel getransporteerd kan worden. Daarom is eerst de ijzerconcentratie in de waterfase, verkregen na centrifugeren en filtreren van ijzerslib, bepaald. Hieruit blijkt dat minder dan $1 \%$ van het ijzer zich in de waterfase bevindt. Ook is het DTPA-extraheerbare ijzergehalte - een indicator voor de ijzerbeschikbaarheid - bepaald, waaruit blijkt dat ijzerslib voor minder dan 4\% oplosbaar is met DTPA. Vervolgens is gekeken naar de effecten van HumVi op het gedrag en de 'oplosbaarheid' van ijzerhydroxiden. Voor deze testen is HumVi, dat voor $84 \%$ uit fulvozuren bestaat, in hoeveelheden van 5 tot $25 \mathrm{v} / \mathrm{v} \%$ gemengd met ijzerspoelwater en ijzerslib. Deze testen gaven een zeer opvallend resultaat. Na toevoeging van HumVi werd een zeer sterke toename in de ijzerconcentratie in het door centrifugeren verkregen supernatant waargenomen. Afhankelijk van de locatie en mengverhouding bevond $10-40 \%$ van het ijzer zich in het supernatant, tegen $<1 \%$ voor ijzerslib monster zónder HumVi.

Verder onderzoek wijst uit dat het ijzer in het supernatant van Fe-HumVi-mengsels bestaat uit zeer kleine Fe-hydroxide deeltjes die door het toegediende fulvozuur gestabiliseerd worden, waardoor 
coagulatie en uitzakken wordt voorkomen. Circa de helft van de ijzerdeeltjes in Fe-HumVi is dusdanig klein dat deze geclassificeerd kunnen worden als nanodeeltjes. In eerste instantie werd verwacht dat het Fe-HumVi-product zou bestaan uit $\mathrm{Fe}^{3+}$-fulvozuur-complexen. Verder onderzoek (o.a. op basis van de theoretische bindingscapaciteit van fulvozuur) wijst echter uit dat minder dan $1 \%$ van het ijzer via complexvorming gebonden is aan fulvozuur. Deze bevinding betekent dat de ijzerspeciatie in het FeHumVi-product duidelijk afwijkt van andere ijzer-humuszuurproducten die eerdere in de literatuur zijn beschreven (Pinton, 1999).

Daarna zijn testen uitgevoerd waarbij Fe-HumVi aan grond is toegevoegd om zo de stabiliteit van de Fe-HumVi-producten in grond te bepalen, t.o.v. commerciële ijzerchelaten. Hiermee wordt getest of Fe-HumVi, evenals ijzerchelaten, in staat is om de ijzerconcentratie in het bodemvocht gedurende een aantal weken te verhogen. Om analyse van de waterfase in de grond mogelijk te maken, is er water toegevoegd aan de grond zodat een suspensie (grond/water; $1: 10$, test 1 ) of een slurry (grond/water $1: 2$, test 2) ontstaat. Uit deze testen blijkt dat Fe-HumVi in staat is om de ijzerconcentratie in bodemvocht sterk te verhogen, maar dit effect treedt niet bij alle grondsoorten op. In een aantal gronden wordt na 14 dagen nog 50 tot $80 \%$ van het gedoseerde ijzer in de waterfase teruggevonden, in andere gronden is dit minder dan $5 \%$. De verschillen in stabiliteit van Fe-HumVi tussen verschillende gronden kunnen nog niet verklaard worden op basis van bodemeigenschappen. Onder dezelfde condities blijft het ijzerchelaat Fe-DPTA voor 50-100\% stabiel (minder stabiel bij hogere $\mathrm{pH}$ ) en Fe-HBED voor $90-100 \%$. Bij deze testen moet worden opgemerkt dat er extra water aan de grond is toegevoegd om analyse van de waterfase mogelijk te maken. Hierdoor wijkt het vochtgehalte af van het vochtgehalte van bodems in het veld, waardoor de resultaten niet een-op-een te vertalen zijn naar veldcondities.

Samengevat: ijzerslib bestaat grotendeels uit ijzerhydroxide nanodeeltjes die onder normale omstandigheden aggregeren en uitzakken. Door toevoeging van HumVi ontstaat een product waarin ijzerdeeltjes gestabiliseerd worden en zodoende in oplossing blijven. Afhankelijk van de grondsoort is Fe-HumVi in staat om het ijzergehalte in de waterfase van de grond (bepaald onder condities waarbij extra water is toegevoegd) te verhogen. Toepassing van ijzerslib zonder HumVi leidt niet tot een verhoging van de ijzerconcentratie in de waterfase van de bodem. Zowel voor ijzerslib als Fe-HumVi geldt dat alleen potproeven met ijzer-deficiënte grond en ijzerbehoeftige gewassen uitsluitsel kunnen geven over de werkzaamheid van deze producten als ijzermeststof. 


\section{Literatuur}

Colombo, C., Palumbo, G., Sellitto, V.M., Rizzardo, C., Tomasi, N., Pinton, R., Cesco, S., 2012. Characteristics of Insoluble, High Molecular Weight Iron-Humic Substances used as Plant Iron Sources. Soil Science Society of America Journal 76(4), 1246.

Díaz, I., del Campillo, M.C., Cantos, M., Torrent, J., 2009. Iron deficiency symptoms in grapevine as affected by the iron oxide and carbonate contents of model substrates. Plant and Soil 322(1-2), 293-302.

Green, R.L., Hartwig, R.C., Richie, W.E., Loeppert, R.H., Beard, J.B., 1998. A selection procedure for iron-deficiency stress tolerance among warm-season turfgrasses using ferrihydrite-amended growth media. HortScience 33(5), 841-844.

Lindsay, W.L., Norvell, W.A., 1978. Development of a DTPA soil test for zinc, iron manganese and copper. Soil Sci. Soc. Am. J. 42.

Pinton, R., Cesco, S., Santi, S., Agnolon, F., Varanini, Z., 1999. Water-extractable humic substances enhance iron deficiency responses by Fe-deficient cucumber plants. Plant and Soil 210, 145-157.

Regelink, I.C., 2014. Natural nanoparticles in soils and their role in organic-mineral interactions and colloid-facilitated transport, PhD thesis Wageningen University, Wageningen.

Schenkeveld, W.D.C., Temminghoff, E.J.M., Reichwein, A.M., van Riemsdijk, W.H., 2010. FeEDDHAfacilitated Fe uptake in relation to the behaviour of FeEDDHA components in the soil-plant system as a function of time and dosage. Plant and Soil 332(1-2), 69-85.

Tomasi, N., De Nobili, M., Gottardi, S., Zanin, L., Mimmo, T., Varanini, Z., Römheld, V., Pinton, R., Cesco, S., 2012. Physiological and molecular characterization of Fe acquisition by tomato plants from natural Fe complexes. Biology and Fertility of Soils 49(2), 187-200.

Tomasi, N., Mimmo, T., Terzano, R., Alfeld, M., Janssens, K., Zanin, L., Pinton, R., Varanini, Z., Cesco, S., 2014. Nutrient accumulation in leaves of Fe-deficient cucumber plants treated with natural Fe complexes. Biology and Fertility of Soils 50(6), 973-982.

Van Zomeren, A., Comans, R.N., 2007. Measurement of humic and fulvic acid concentrations and dissolution properties by a rapid batch procedure. Environmental science \& technology 41(19), 6755-6761.

Vempati, R.K., Loeppert, R.H., 1986. Synthetic ferrihydrite as a potenital iron amendment in calcareous soils. Journal of Plant Nutrition 9(3-7), 1039-1052. 
Wageningen Environmental Research Postbus 47

6700 AA Wageningen

T 0317480700

www.wur.nl/environmental-research

Wageningen Environmental Research Rapport 2875

ISSN 1566-7197
De missie van Wageningen University \& Research is 'To explore the potential of nature to improve the quality of life'. Binnen Wageningen University \& Research bundelen Wageningen University en gespecialiseerde onderzoeksinstituten van Stichting Wageningen Research hun krachten om bij te dragen aan de oplossing van belangrijke vragen in het domein van gezonde voeding en leefomgeving. Met ongeveer 30 vestigingen, 5.000 medewerkers en 10.000 studenten behoort Wageningen University \& Research wereldwijd tot de aansprekende kennisinstellingen binnen haar domein. De integrale benadering van de vraagstukken en de samenwerking tussen verschillende disciplines vormen het hart van de unieke Wageningen aanpak. 



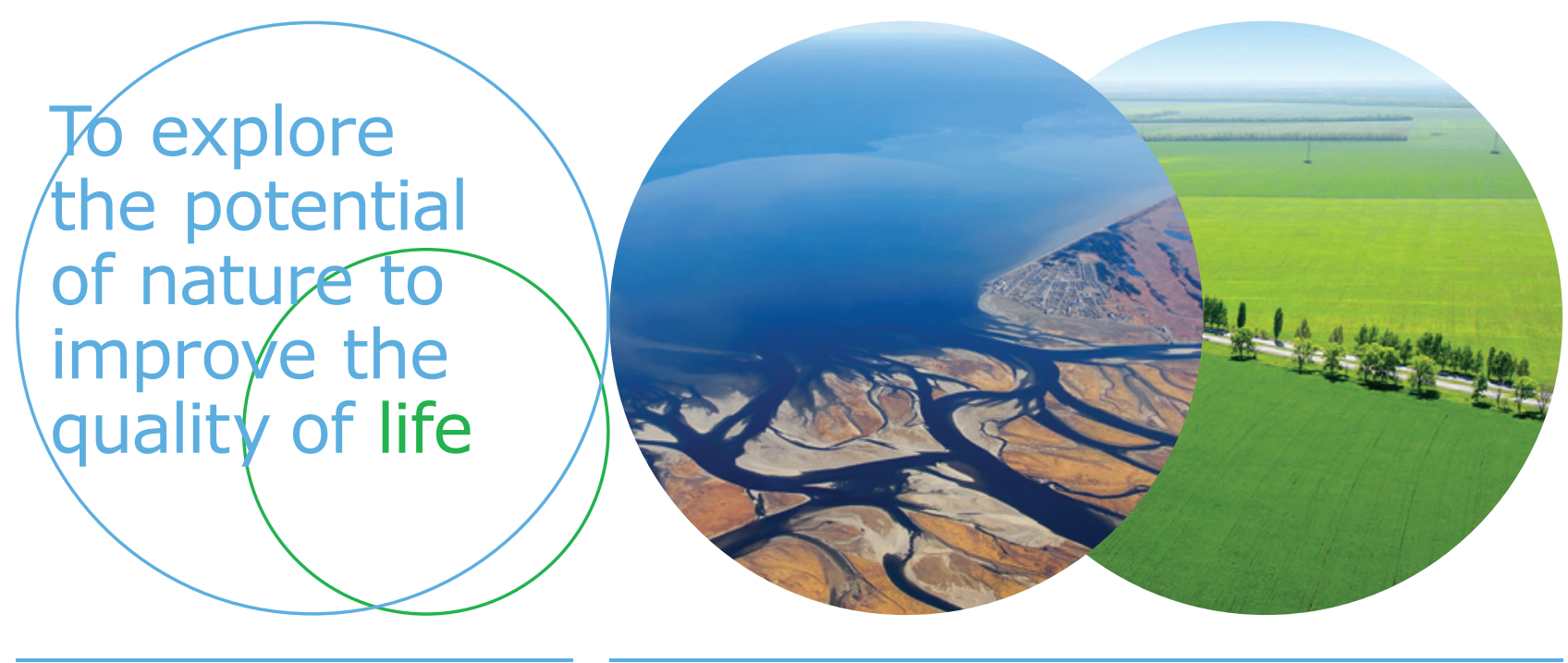

Wageningen Environmental Research Postbus 47

$6700 \mathrm{AB}$ Wageningen

T 317480700

www.wur.nl/environmental-research

Rapport 2875

ISSN 1566-7197
De missie van Wageningen University \& Research is 'To explore the potential of nature to improve the quality of life'. Binnen Wageningen University \& Research bundelen Wageningen University en gespecialiseerde onderzoeksinstituten van Stichting Wageningen Research hun krachten om bij te dragen aan de oplossing van belangrijke vragen in het domein van gezonde voeding en leefomgeving. Met ongeveer 30 vestigingen, 5.000 medewerkers en 10.000 studenten behoort Wageningen University \& Research wereldwijd tot de aansprekende kennisinstellingen binnen haar domein. De integrale benadering van de vraagstukken en de samenwerking tussen verschillende disciplines vormen het hart van de unieke Wageningen aanpak. 